\title{
Cancer Susceptibility Mutations in Patients With Urothelial Malignancies
}

Maria I. Carlo, MD ${ }^{1}$; Vignesh Ravichandran, MS ${ }^{1}$; Preethi Srinavasan, MS ${ }^{1}$; Chaitanya Bandlamudi, PhD ${ }^{1}$; Yelena Kemel, ScM ${ }^{1}$; Ozge Ceyhan-Birsoy, PhD ${ }^{1}$; Semanti Mukherjee, PhD ${ }^{1}$; Diana Mandelker, MD, PhD ${ }^{1}$; Joshua Chaim, DO ${ }^{1}$; Andrea Knezevic, MS ${ }^{1}$; Satshil Rana, MS ${ }^{1}$; Zarina Fnu, MS ${ }^{1}$; Kelsey Breen, MS ${ }^{1}$; Angela G. Arnold, MS ${ }^{1}$; Aliya Khurram, MBBS ${ }^{1}$; Kaitlyn Tkachuk ${ }^{1}$; Catharine K. Cipolla ${ }^{1}$; Ashley Regazzi ${ }^{1}$; A. Ari Hakimi, MD ${ }^{1}$; Hikmat Al-Ahmadie, MD ${ }^{1}$; Guido Dalbagni, MD ${ }^{1}$; Karen A. Cadoo, MD ${ }^{1}$; Michael F. Walsh, MD ; Min-Yuen Teo, MBBCh ${ }^{1}$; Samuel A. Funt, MD ${ }^{1}$; Jonathan A. Coleman, MD ${ }^{1}$; Bernard H. Bochner, MD ${ }^{1}$; Gopa lyer, MD ${ }^{1}$; David B. Solit, MD ${ }^{1}$; Zsofia K. Stadler, MD ${ }^{1}$; Liying Zhang, MD ${ }^{1}$; Jonathan E. Rosenberg, MD ${ }^{1}$; Barry S. Taylor, PhD Mark E. Robson, MD ${ }^{1}$; Michael F. Berger, PhD ${ }^{1}$; Joseph Vijai, PhD ${ }^{1}$; Dean F. Bajorin, MD ${ }^{1}$; and Kenneth Offit, MD, MPH ${ }^{1}$

PURPOSE Urothelial cancers (UCs) have a substantial hereditary component, but, other than their association with Lynch syndrome, the contribution of genetic risk factors to UC pathogenesis has not been systematically defined. We sought to determine the prevalence of pathogenic/likely pathogenic (P/LP) germline variants in patients with UC and identify associated clinical factors.

PATIENTS AND METHODS Overall, 586 patients with UC underwent prospective, matched tumor-normal DNA sequencing. Seventy-seven genes associated with cancer predisposition were analyzed; allele frequencies were compared with publicly available database.

RESULTS P/LP germline variants were identified in 80 (14\%) of 586 individuals with UC. The most common P/LP variants in high-or moderate-penetrance genes were BRCA2 $(\mathrm{n}=9 ; 1.5 \%), \operatorname{MSH} 2(\mathrm{n}=8 ; 1.4 \%), B R C A 1(\mathrm{n}=8$; $1.4 \%), \operatorname{CHEK} 2(\mathrm{n}=6 ; 1.0 \%), E R C C 3(\mathrm{n}=4 ; 0.7 \%)$, and $N B N$ and $R A D 50(\mathrm{n}=3 ; 0.5 \%$ each). Sixty-six patients (83\%) had germline P/LP variants in DNA-damage repair (DDR) genes, of which 28 (42\%) had biallelic inactivation. Patients with P/LP variants were more commonly diagnosed at an early age $(22 \% v 6 \%$ in those without variants; $P=.01$ ). BRCA2 and $M S H 2$ were significantly associated with an increased risk for UC (odds ratio, $3.7[P=.004]$ and $4.6[P=.001]$, respectively). Current clinical guidelines for referral for genetic testing failed to identify $6(26 \%)$ patients with high-penetrance variants.

CONCLUSION Clinically significant P/LP germline variants in DDR genes frequently are present in patients with advanced UC. The presence of DDR germline variants could guide cancer screening for patients and their families and serve as predictive biomarkers of response to targeted or immunotherapies. Family history-based criteria to identify patients with hereditary UC susceptibility are insensitive. Broader germline testing in UC, particularly in those of young ages, should be considered.

J Clin Oncol 38:406-414. @ 2019 by American Society of Clinical Oncology

\section{INTRODUCTION}

Urothelial cancer (UC) has a substantial hereditary component, with an estimated $30 \%$ heritable fraction according to epidemiologic studies. ${ }^{1}$ Family history of

ASSOCIATED

CONTENT

Appendix

Author affiliations

and support

information (if

applicable) appear

at the end of this

article.

Accepted on

November 6, 2019

and published at

ascopubs.org/journal/

jco on December 3,

2019: DOI https://doi.

org/10.1200/JCO.19.

01395
UC confers a twofold increased risk, with numerous reports of multiple-case UC kindreds. ${ }^{2-6}$ The heritable mechanisms underlying familial aggregations and early-onset UC remain unknown, and there are few syndromic associations with known cancer susceptibility genes. Highly penetrant cancer susceptibility genes, such as those in the mismatch-repair (MMR) pathway, only account for a small fraction of inherited UC susceptibility; mutations in MMR-associated genes are found primarily in patients with tumors of the ureter and renal pelvis. ${ }^{7,8}$

Beyond their role in tumor pathogenesis, germline variants can be predictors of response to cancer therapies that have activities enhanced by DNA repair defects. ${ }^{9,10}$ Deficient MMR status and high microsatellite instability (MSI-H), hallmarks of tumors in patients with Lynch syndrome, are predictive of response to the PD-1 inhibitor pembrolizumab. ${ }^{11}$ In UC, inactivating somatic mutations in ERCC2, ATM, RB1, and FANCC have been associated with response to cisplatin-based neoadjuvant chemotherapy. ${ }^{12,13}$ DNAdamage repair (DDR) mutations, both somatic and germline, may independently predict response to checkpoint inhibitors in patients with UC. ${ }^{14}$ The substantial heritability of UC, the incomplete understanding of the genes and pathways responsible for this increased heritable risk, and the potential that identification of germline variants could help guide therapeutic decisions provide a strong rationale to investigate putative UC susceptibility genes.

We have shown that germline mutations are commonly identified in individuals undergoing tumor-normal next-generation sequencing (NGS) and may reveal

\section{ASCO}


previously unknown genetic associations. ${ }^{15,16}$ Using a matched tumor-germline NGS platform, we determined the prevalence of pathogenic/likely pathogenic (P/LP) germline variants in 77 cancer-associated genes in patients with UC, and we examined associations between germline status and somatic mutational profile.

\section{PATIENTS AND METHODS}

\section{Patient Cohort}

Beginning in May 2014, patients with UC seen at Memorial Sloan Kettering Cancer Center were offered matched tumor-germline DNA sequencing at physician discretion under an institutional protocol (ClinicalTrials.gov identifier: NCT01775072), with only somatic variants reported. Baseline clinical characteristics for all enrolled patients were collected from institutional electronic medical records. Age $\leq 45$ years was prospectively defined as early onset (outside the $95 \% \mathrm{Cl}$ of the median age of UC diagnosis). ${ }^{17}$ Starting in May 2015, patients could opt in to receive results of a secondary germline analysis of genes associated with increased heritable cancer risk; 169 patients consented to disclosure of germline results. For these 169 patients (identified cohort), germline variants were associated with a broad range of clinical features. For the remaining 417 patients (anonymized cohort), analysis was performed in a permanently anonymized fashion with no clinical annotation beyond tumor subtype. The study was approved by the Memorial Sloan Kettering Cancer Center institutional review board.

\section{Sequencing and Results Reporting}

Paraffin-embedded tumor and blood from patients were obtained and sequenced using the MSK-IMPACT platform, a capture-based NGS assay capable of identifying mutations, copy number alterations, and select gene fusions involving 341 cancer-associated genes in the first iteration and 468 in the more recent iteration, as described previously (gene list; Appendix Table A1, online only). ${ }^{18,19}$ For the anonymized cases, sequence data were assigned a unique study identifier and irretrievably de-linked from personal identifiers before variant calling.

\section{Variant Interpretation}

Pathogenicity was determined according to American College of Medical Genetics criteria (updated as of January 2018). ${ }^{20}$ Germline variants in 77 cancer predisposition genes were prioritized using PathoMAN, an automated germline variant classification tool for cancer; variants from the Exome Aggregation Consortium (ExAC) database without The Cancer Genome Atlas (TCGA) alleles were similarly prioritized. ${ }^{21}$ In addition, manual curation of the dataset was performed by a research genetic counselor (Y.K.), and any differences in variant calls were resolved with review by a molecular geneticist (O.C.B.) and a cancer geneticist (M.I.C.). For these 77 genes, all coding regions were sequenced in both the germline and the tumor. P/LP germline variants (associated with disease causation) were included in this analysis; variants of unknown significance were reviewed but were not reported. According to known disease risks and prior modeling, P/LP variants were classified at the gene level as high penetrance (relative risk $[R R]$ of disease, $>4$ ), moderate penetrance (RR, 2-4), lowpenetrance $(R R,<2)$, or uncertain penetrance, or they were associated with an autosomal recessive condition. ${ }^{22}$ For CHEK2, APC, and ERCC3, classification was performed at the variant level: APC p.lle1307Lys and CHEK2 p.lle157Thr were considered low or uncertain penetrance, and the ERCC3 p.Arg109X, moderate penetrance. ${ }^{23}$ Tumor sequencing results were available for all patients. The FACETS algorithm was used to evaluate loss of heterozygosity $(\mathrm{LOH})$ at the locus of the germline variant. ${ }^{24}$

We identified 34 genes within the MSK-IMPACT panel as related to DDR, as previously described (Appendix Table A2, online only). ${ }^{25}$ Within DDR genes, MSH2, MSH6, MLH1, and PMS2 were classified as MMR pathway genes; the remaining DDR genes were classified as other DDR.

\section{Comparison of Guidelines Based Versus Agnostic Testing for Cancer Predisposition Syndromes in the Identified Cohort}

Family history, religion, and race/ethnicity were selfreported and collected from the medical record or at time of genetic counseling. Published guidelines based on personal and family history were used to determine which genetic tests would be indicated according to the age at onset of cancer, personal or family history of cancer, and self-reported Ashkenazi Jewish ancestry. ${ }^{26,27}$ A pathogenic variant was considered incremental if it was detected by sequencing in this study but would not have been identified by genetic testing through application of current clinical guidelines.

\section{Statistical Analysis}

Allele frequencies of P/LP variants in the identified and anonymized cohorts were compared with allele frequencies of P/LP variants in the ExAC without cases from TCGA, as described previously. ${ }^{21}$ Ashkenazi Jewish founder mutations were excluded (Appendix Table A3, online only). Fisher's exact 2-sided test was performed to assess differences in frequency; odds ratios with 95\% intervals were reported. The $\alpha$ used to determine statistical significance in the Fisher's test and the 95\% confidence limits was adjusted using the Bonferroni correction for multiple comparisons. In the identified cohort, clinical characteristics of patients with germline P/LP variants were compared with those without them using Fisher's exact test. Statistical analysis was performed using SAS 9.4 (Cary, NC) and R version 3.3.3. Response to therapy in identified patients with MMR mutations treated with immunotherapy was assessed according to RECIST v1.1 criteria. 


\section{RESULTS}

\section{Patient Characteristics}

Five hundred eighty-six patients had tumor-germline profiling using MSK-IMPACT; 417 consented to receive only tumor sequencing results (anonymized cohort), and 169 consented to receive both tumor and germline sequencing results (identified cohort). Clinical characteristics of patients are listed in Table 1. Patients were primarily men (74.1\%) and had a median age of 63 years (range, 25-87 years); 42 (7.2\%) were $\leq 45$ years of age. Only 42 patients (7.2\%) had a family history of bladder or UC, and 112 (19.1\%) had a history of a second malignancy other than UC. Most patients $(79.0 \%)$ had bladder as the primary tumor site, and $59.7 \%$ had or developed metastatic disease during the period of clinical follow-up.

\section{Frequency and Spectrum of Germline Variants}

Eighty-six P/LP variants were identified in 80 individuals (13.7\%), including 62 patients (13.4\%) with bladder and 18 (15.8\%) with upper tract (UT) tumors (Fig 1). Eleven patients had two P/LP variants each. The most frequently mutated moderate- or high-penetrance genes were $B R C A 2$ $(\mathrm{n}=9 ; 1.5 \%), \operatorname{MSH} 2(\mathrm{n}=8 ; 1.4 \%)$, BRCA1 $(\mathrm{n}=8 ; 1.4 \%)$, CHEK2 $(n=6 ; 1.0 \%), \operatorname{ERCC3}(\mathrm{n}=4 ; 0.7 \%)$, and NBN and $\operatorname{RAD50}(\mathrm{n}=3 ; 0.5 \%$ each; Appendix Table A4, online only). The low-penetrance variant $A P C$ p.lle1307Lys was the most prevalent overall $(n=11)$, and $6(35.3 \%)$ of the 17 BRCA1/2 variants were Ashkenazi Jewish founder mutations. Of all variants, 35 (40.7\%) were of high penetrance, 24 (27.9\%) were of moderate penetrance, $18(20.9 \%)$ were of low or uncertain penetrance, and $10(11.6 \%)$ were in a gene associated with an autosomal recessive cancer-associated syndrome. Sixty-five variants $(75.6 \%)$ were in genes associated with DDR; of these, 12 were in the MMRassociated genes MSH2 $(n=8), \operatorname{MSH6}(n=2)$, and MLH1 ( $\mathrm{n}=2$; Fig 2A).

\section{Correlation Between Germline Genotype and Tumor Phenotype}

Of 54 germline variants in DDR genes (excluding MMR genes), $\mathrm{LOH} /$ somatic mutation in the tumor was present in 18 patients (33.3\%), including carriers of $A T M(n=2$ of 3$)$, ERCC2 $(\mathrm{n}=3$ of 3$), B R C A 2(\mathrm{n}=6$ of 9$)$, and BRCA1 $(\mathrm{n}=2$ of 8 ), among others (Fig $2 \mathrm{~B}$ ). In the identified cohort, all tumors from patients with a germline MMR variant had either MSI-H status or immunohistochemistry showing deficient MMR protein staining.

\section{Estimate of UC Risk Associated With Observed Variants}

To estimate population frequencies of germline P/LP variants in genes seen in the UC cohort, we analyzed allele frequencies of these genes in the ExAC dataset. BRCA2 and $M S H 2$ showed statistically significant increased risk in UC patients compared with ExAC (odds ratio, 3.7; $95 \% \mathrm{Cl}$, 1.5 to $7.8 ; P<.003$ for BRCA2; and odds ratio, $4.6 ; 95 \%$ $\mathrm{Cl}, 1.8$ to $9.8 ; P<.001$ for $M S H 2$; Table 2).

\section{Clinical Characteristics Associated With P/LP Variants}

The only clinical characteristic available for analysis for patients in the anonymized cohort was site of tumor. In patients with bladder primaries from both the anonymized and identified cohorts, 39 (8.4\%) had moderate- or highrisk P/LP variants. Conversely, in patients with UT primaries, 16 (14.0\%) had moderate- or high-risk P/LP variants, including 10 (8.8\%) with MMR mutations.

In the identified cohort, patients with P/LP variants were more likely to have early age of onset (age $\leq 45$ years) compared with patients with no germline variant $(22 \% \mathrm{v}$ $6 \% ; P=0.01$; Table 3). Six of 14 patients with early-onset UC had germline variants, including in $M S H 2(n=2)$, BRCA1 $(n=2), \operatorname{MSH6}(n=1)$, and BRCA2 $(n=1)$. Presence of $P / L P$ variants was not statistically significantly associated with a positive family history of UC, non-UC malignancy, smoking history, or metastasis at diagnosis, but presence was associated with Ashkenazi Jewish ancestry, reflective of founder mutations in BRCA1, BRCA2, and CHEK2.

Of 9 patients with MMR variants in the identified cohort, all but one had a UT tumor as the primary site of malignancy. The median age of diagnosis of UC was 58 years (range, 31-84 years), and UC was the first malignancy in 6 patients. Although none reported a family history of bladder or UT cancer, 4 reported relatives with cancers of unknown origin or kidney cancer, not otherwise specified.

Given the association of MSI-H status or deficient MMR tumors and response to immunotherapy in other malignancies, we explored response in the four patients in the identified cohort who had germline MMR variants (all MSI-H tumors) and who had received immunotherapy. All 4 had presented initially with metastatic disease and had received platinum chemotherapy as first-line treatment. Three experienced progression of disease after platinum chemotherapy followed by a complete response after immunotherapy (Appendix Fig A1, online only). The fourth patient experienced progression of disease on both platinum chemotherapy and immunotherapy.

\section{Comparisons to Clinical Genetics Referral Criteria}

In the identified cohort, detailed family history was obtained by interview for 29 (85.3\%) of the patients with P/LP variants; for the remainder of patients, data were extracted from the electronic medical record. Only 9 of 27 patients with high- or moderate-penetrance variants had undergone clinical genetic testing or attended clinical genetic counseling before receiving genetic test results through the protocol. Of patients with high-penetrance P/LP variants, 6 patients (26.3\%) would not have been referred for germline testing according to published guidelines (one each with MSH2, MSH6, BRCA1, SDHA, and TP53). The patient with a TP53 variant, diagnostic of Li-Fraumeni syndrome, had a father with bladder cancer, but the patient did not meet criteria for any genetic testing. Of patients with 
TABLE 1. Patient Characteristics

No. (\%)

\begin{tabular}{|c|c|c|c|}
\hline Characteristic & $\begin{array}{l}\text { Identified Cohort } \\
\quad(n=169)\end{array}$ & $\begin{array}{l}\text { Anonymized Cohort } \\
\qquad(n=417)\end{array}$ & $\begin{array}{c}\text { Total } \\
(\mathrm{N}=586)\end{array}$ \\
\hline \multicolumn{4}{|l|}{ Age, years } \\
\hline Median (range) & $63(31-84)$ & $64(25-87)$ & $63(25-87)$ \\
\hline$\leq 45$ years & $14(8.3)$ & $28(6.7)$ & $42(7.2)$ \\
\hline$\geq 46$ & $155(91.7)$ & $388(93.0)$ & $543(92.7)$ \\
\hline \multicolumn{4}{|l|}{ Sex } \\
\hline Female & $41(24.3)$ & $111(26.6)$ & $152(25.9)$ \\
\hline Male & $128(75.7)$ & $306(73.4)$ & $434(74.1)$ \\
\hline \multicolumn{4}{|l|}{ Race or ethnic background } \\
\hline White & $146(86.4)$ & $366(87.8)$ & $512(87.4)$ \\
\hline Hispanic & $2(1.2)$ & $4(1.0)$ & $6(1.0)$ \\
\hline African American & $5(3.0)$ & $13(3.1)$ & $18(3.1)$ \\
\hline Asian or Pacific Islander & $5(3.0)$ & $12(2.9)$ & $17(2.9)$ \\
\hline Other or unknown & $11(6.5)$ & $22(5.3)$ & $33(5.6)$ \\
\hline \multicolumn{4}{|l|}{ Ashkenazi Jewish ancestry } \\
\hline Yes & $31(18.3)$ & $76(18.2)$ & 107 (18.3) \\
\hline No & $97(57.4)$ & $220(52.8)$ & $317(54.1)$ \\
\hline Unknown & $41(24.3)$ & $121(29.0)$ & $162(27.7)$ \\
\hline \multicolumn{4}{|l|}{ Other primary malignancy } \\
\hline Yes & $39(23.1)$ & $73(17.5)$ & $112(19.1)$ \\
\hline No & $130(76.9)$ & $343(82.3)$ & $473(80.7)$ \\
\hline Unknown & 0 & $1(0.2)$ & $1(0.2)$ \\
\hline \multicolumn{4}{|l|}{ Family history of urothelial cancer } \\
\hline Yes & $18(10.7)$ & $24(5.8)$ & $42(7.2)$ \\
\hline No & $151(89.3)$ & $391(93.8)$ & $542(92.5)$ \\
\hline Unknown & 0 & $2(0.5)$ & $2(0.3)$ \\
\hline \multicolumn{4}{|l|}{ Tobacco use history } \\
\hline Ever & $103(60.9)$ & $273(65.5)$ & $376(64.2)$ \\
\hline Never & $66(39.1)$ & $142(34.1)$ & $208(35.5)$ \\
\hline Unknown & 0 & $2(0.5)$ & $2(0.3)$ \\
\hline \multicolumn{4}{|l|}{ Site of primary malignancy } \\
\hline Bladder/urethra & $117(69.2)$ & $346(83.0)$ & $463(79.0)$ \\
\hline Renal pelvis/ureter & $48(28.4)$ & $66(15.8)$ & $114(19.5)$ \\
\hline Both or unknown & $4(2.4)$ & $5(1.2)$ & $9(1.5)$ \\
\hline \multicolumn{4}{|l|}{ Histologic subtype } \\
\hline Urothelial carcinoma & 169 (100.0) & $393(94.2)$ & $562(95.9)$ \\
\hline Adenocarcinoma & 0 & $16(3.8)$ & $16(2.7)$ \\
\hline Other & 0 & $8(1.9)$ & $8(1.4)$ \\
\hline \multicolumn{4}{|l|}{ Stage at diagnosis } \\
\hline Non-muscle invasive bladder & $44(26.0)$ & $209(50.1)$ & $253(43.2)$ \\
\hline Muscle-invasive bladder & $56(33.1)$ & $102(24.5)$ & $158(27.0)$ \\
\hline Localized upper tract & $35(20.7)$ & $51(12.2)$ & $86(14.7)$ \\
\hline Metastatic & $34(20.1)$ & $43(10.3)$ & $77(13.1)$ \\
\hline Unknown/other & 0 & $12(2.9)$ & $12(2.1)$ \\
\hline
\end{tabular}


TABLE 1. Patient Characteristics (continued)

No. (\%)

\begin{tabular}{lccr} 
Characteristic & $\begin{array}{c}\text { Identified Cohort } \\
(\mathbf{n = 1 6 9 )}\end{array}$ & $\begin{array}{c}\text { Anonymized Cohort } \\
(\mathbf{n = 4 1 7 )}\end{array}$ & $\begin{array}{c}\text { Total } \\
(\mathbf{N}=\mathbf{5 8 6})\end{array}$ \\
\hline Stage at time of analysis & & & $182(43.7)$ \\
\hline Nonmetastatic & $53(31.4)$ & $234(56.1)$ & $235(40.1)$ \\
\hline Metastatic & $116(68.6)$ & $1(0.2)$ & $350(59.7)$ \\
\hline Unknown & 0 & $1(0.2)$
\end{tabular}

NOTE. Cohort demographic and clinical characteristics are provided for the 586 patients who consented to tumor-normal testing. Patients in the identified cohort additionally consented to receive germline results.

moderate-penetrance variants, $7(87.5 \%)$ would not have been referred (Appendix Table A5, online only).

\section{DISCUSSION}

This study shows that, in patients with UC, clinically significant P/LP germline variants, particularly in DDR genes, frequently are present. Multiple epidemiologic studies have identified an increased familial risk of UC. However, to date, the only identified hereditary cancer syndrome associated with increased UC risk is Lynch syndrome, which is caused by inactivating mutations in the MMR-associated genes MSH2, MSH6, MLH1, PMS2, and EPCAM. ${ }^{3,28,29}$ Patients with Lynch syndrome have an up to $12 \%$ cumulative risk of urinary tract cancer; although the risk is greater for UT UC, there also may be an increased risk for bladder UC. . $^{7,80,31}$ Studies estimating prevalence of Lynch syndrome in patients with UC, however, have been limited. In two studies looking at unselected patients with UT UC, 7\% of tumors had deficient MMR protein expression or were MSI-H, usually a necessary but not sufficient biomarker for Lynch syndrome. ${ }^{32,33}$ In our study, $2.1 \%$ overall and $8.7 \%$ of patients with UT tumors had Lynch syndrome, and, for those in the identified cohort, 6 of 9 had UC as the first malignancy. Immunohistochemistry analysis of tumors for loss of MMR protein expression or tumor MSI analysis is standard practice for colorectal and endometrial cancers, for which the incidence of Lynch syndrome ranges from $2 \%$ to $5 \% .{ }^{34} \mathrm{~A}$ recent pan-cancer study showed that, among patients with MSI-high/intermediate UC, $37.5 \%$ had a germline MMR variant diagnostic of Lynch syndrome, the highest prevalence of all cancer types analyzed. ${ }^{35}$ The increased incidence of Lynch syndrome in our cohort, and the high prevalence of Lynch syndrome in those with MSI-high/intermediate tumors, supports consideration of germline or tumor screening for those with UT UC.

In our cohort, $9 \%$ of patients had a germline DDR mutation in a gene other than those in MMR. Dysregulation of DNA repair is implicated in the carcinogenesis of UC. DDR somatic mutations are frequent in UC. ${ }^{25,36}$ For example, the nucleotide excision repair pathway gene ERCC2 was somatically mutated in $9 \%$ of UC in TCGA, and common polymorphisms in ERCC2, NBN, and XPC are associated

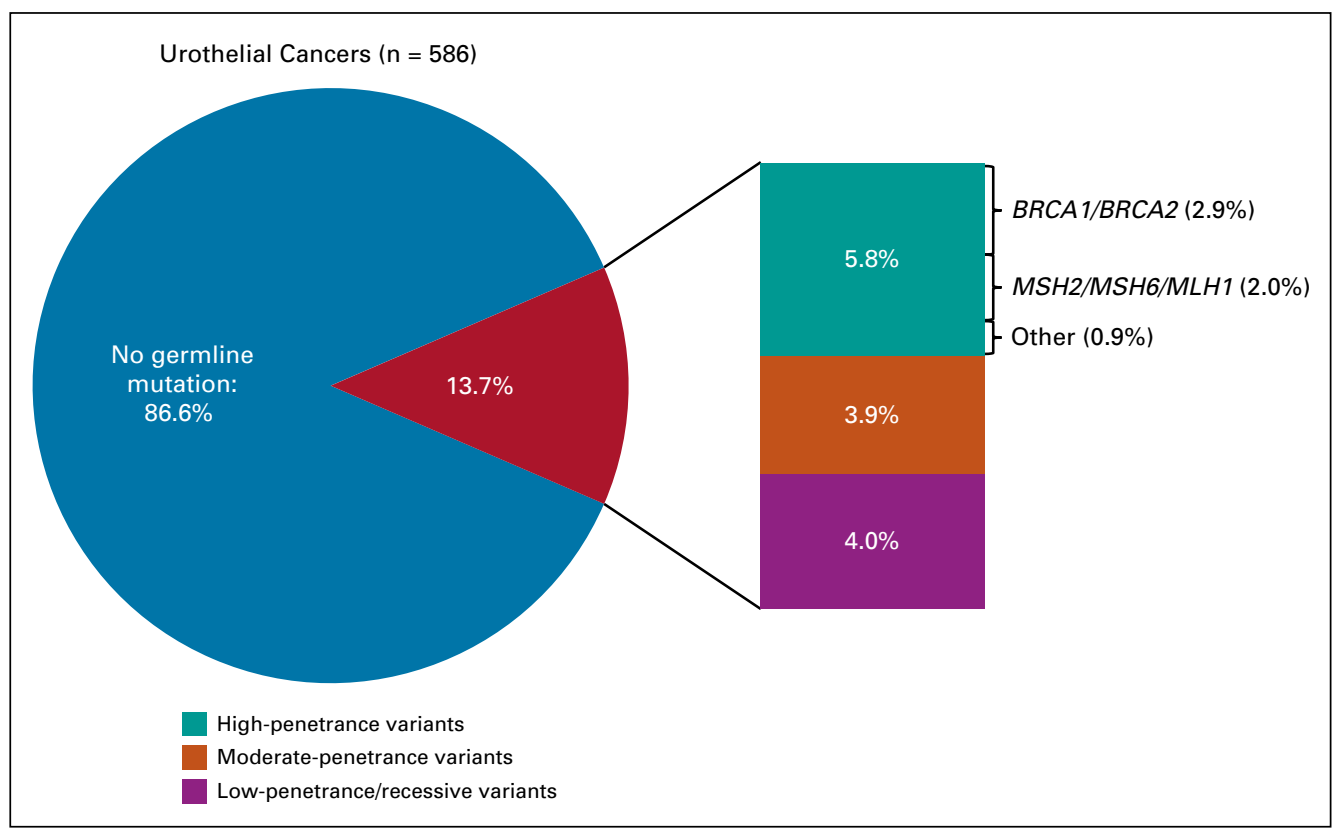

FIG 1. Frequency and penetrance of germline variants in patients with urothelial cancer. Frequency of pathogenic/likely pathogenic (P/LP) germline variants identified in 586 patients with UC. Pie chart shows that $13.7 \%$ ( $n=80$ patients) had a germline P/LP variant; 9.7\% $(n=57)$ had high- or moderate-penetrance variants. 


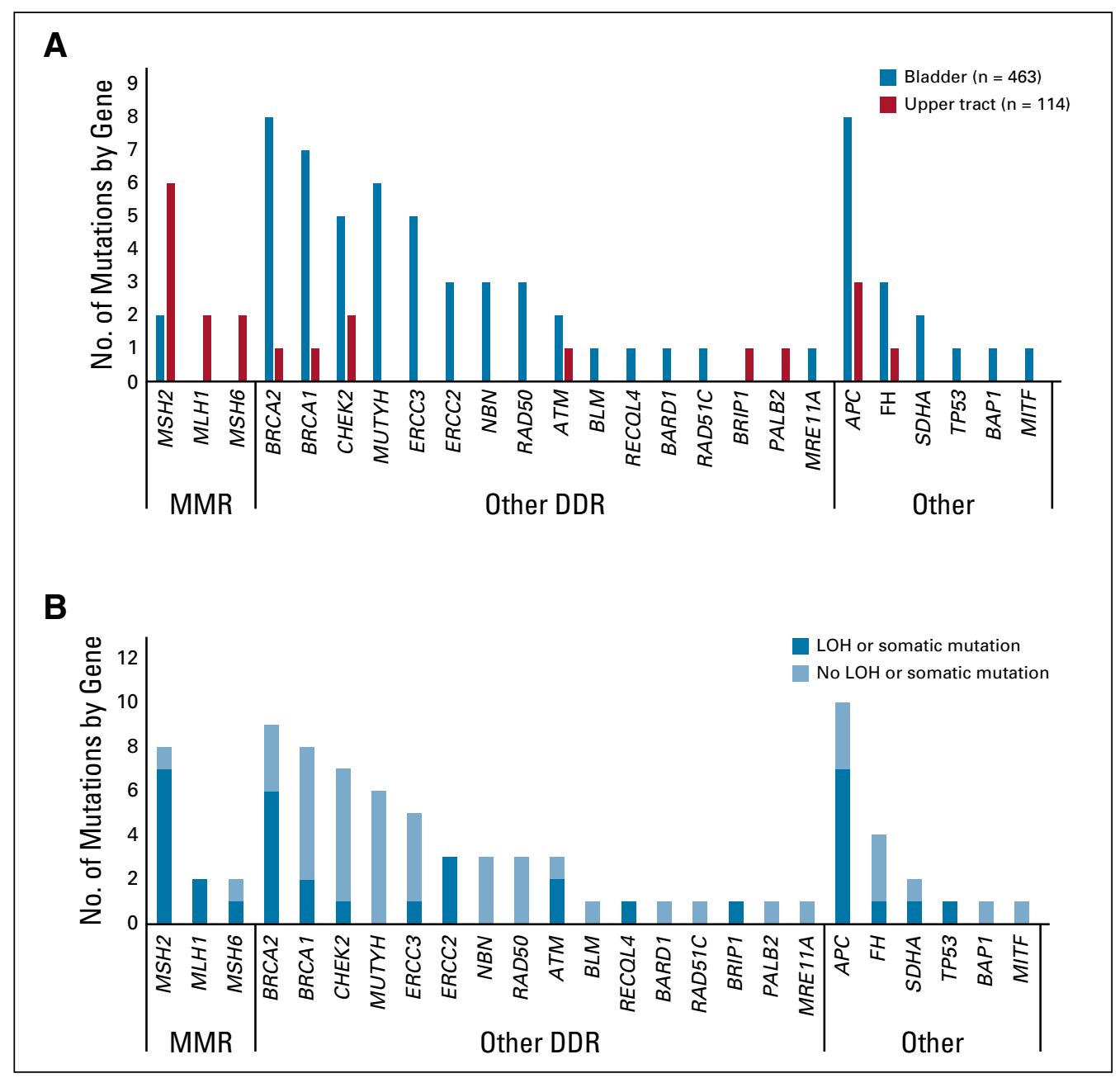

FIG 2. Germline pathogenic/likely pathogenic variants by site of tumor origin and tumors with loss of heterozygosity $(\mathrm{LOH})$ or second somatic mutation in the tumor in 586 patients. (A) Number of mutations in each gene by tumor type and $(\mathrm{B})$ in germline-positive occurrences with $\mathrm{LOH}$ or second somatic mutation in same locus. DDR, DNA-damage repair; MMR, mismatch repair.

with bladder cancer risk. ${ }^{13,37,38}$ To further investigate the pathogenic role of DDR genes, we compared allele frequencies of the most frequently mutated genes in UC with frequencies in individuals in ExAC without cancer, and we found significantly increased frequencies of mutations in
BRCA2 and MSH2 in UC. We also found $\mathrm{LOH}$ in 6 of 9 tumors in patients with germline variants in BRCA2 and 3 of 3 tumors in patients with germline ERCC2 variants. Of note, the current number of carriers is too small to analyze enrichment for second allele loss in tumors for germline

TABLE 2. Comparison of Allele Frequencies in All Patients Versus ExAC

\begin{tabular}{lcccccc} 
Gene & $\begin{array}{c}\text { UC Occurrence } \\
\text { Allele Count }\end{array}$ & $\begin{array}{c}\text { UC Occurrence } \\
\text { Allele Number }\end{array}$ & Allele Count ExAC & Allele ExAC & Odds Ratio (95\% Cl) & P \\
\hline ATM & 3 & 1,172 & 183 & 106,194 & $1.49(0.15$ to 5.7$)$ & .46 \\
\hline$B R C A 1$ & 4 & 1,164 & 85 & 106,206 & $4.29(0.67$ to 14.6$)$ & .02 \\
\hline BRCA2 & 7 & 1,168 & 173 & 106,187 & $3.68(1.01$ to 9.5$)$ & $.004^{*}$ \\
\hline MSH2 & 7 & 1,172 & 133 & 102,035 & $4.58(1.26$ to 11.9$)$ & $.001^{*}$ \\
\hline NBN & 3 & 1,172 & 65 & 106,189 & $4.18(0.43$ to 16.7$)$ & .04 \\
\hline RAD50 & 3 & 1,172 & 392 & 106,179 & $0.69(0.07$ to 2.6)
\end{tabular}

NOTE. Odds ratio and Cls calculated with Bonferroni correction. Only genes with three or more occurrences in the UC cohort were considered. Ashkenazi Jewish BRCA1/2 founder mutations were excluded.

Abbreviation: UC, urothelial carcinoma.

${ }^{*}$ Statistically significant with Bonferroni-corrected $\alpha=.05 / 6=.0083$. 
TABLE 3. Clinical Characteristics by Moderate-/High-Penetrance Variants in Identified Cohort

\begin{tabular}{lccc} 
Characteristic & $\begin{array}{c}\text { Any Moderate/High } \\
\text { Penetrance }(\mathbf{n = 2 7})\end{array}$ & $\begin{array}{c}\text { No Moderate/High } \\
\text { Penetrance }(\mathbf{n = 1 4 2 )}\end{array}$ & $\mathbf{P}$ \\
\hline Age, years & & & \\
\hline$\leq 45$ & $6(22)$ & $8(6)$ & .01 \\
\hline$\geq 46$ & $21(78)$ & $134(94)$ & \\
\hline Sex & & & \\
\hline Male & $19(70)$ & $109(77)$ & .47 \\
\hline Female & $8(30)$ & $33(23)$ &
\end{tabular}

\begin{tabular}{lccc}
\hline $\begin{array}{l}\text { Ashkenazi Jewish } \\
\text { ancestry }\end{array}$ & & & \\
\hline Yes & $11(41)$ & $20(14)$ & .005 \\
\hline No & $13(48)$ & $84(59)$ & \\
\hline Unknown & $3(11)$ & & \\
\hline Tobacco use history & & $88(62)$ & .53 \\
\hline Current or former & $15(56)$ & $54(38)$ & \\
\hline Never & $12(44)$ & & \\
\hline Family history of UC & & $17(12)$ & .74 \\
\hline Yes & $2(7)$ & & \\
\hline No & $25(93)$ & & \\
\hline
\end{tabular}

History of second

malignancy

\begin{tabular}{lccc}
\hline Yes & $7(26)$ & $32(23)$ & .80 \\
\hline No & $20(74)$ & $110(77)$ & \\
\hline $\begin{array}{l}\text { Site of primary } \\
\text { malignancy }\end{array}$ & & & \\
\hline Bladder/urethra & $16(59)$ & $101(72)$ & .32 \\
\hline Renal pelvis/ureter & $11(41)$ & $37(26)$ & \\
\hline Both/unknown & 0 & $2(1)$ & \\
\hline Stage at diagnosis & & & \\
\hline Nonmetastatic & $24(89)$ & $31(22)$ & \\
\hline Metastatic & $3(11)$ & & .12 \\
\hline Stage at last follow-up* & & $41(29)$ & \\
\hline Nonmetastatic & $12(44)$ & $101(71)$ & \\
\hline Metastatic & $15(56)$ & &
\end{tabular}

Abbreviation: UC, urothelial carcinoma.

*Median length of follow-up was 4.1 years (range, 1.5-23.2 years).

events compared with the background loss of first somatic allele in these genes. Pathogenic nucleotide excision repair germline mutations have not been described previously in $\mathrm{UC}$, although heterozygous germline mutations in ERCC2 and ERCC3 have been associated with increased risk of sarcoma and breast cancer. ${ }^{38,39}$ Additional studies will be needed to determine the role of these germline mutations in the pathogenicity of UC.

Germline MMR and other DDR mutations have potential implications for treatment selection. Somatic mutations in
ERCC2, ATM, RB1, FANCC, and other DDR genes are correlated with improved responses to platinum-based chemotherapy in patients with UC. ${ }^{12,13,40,41}$ Whether germline pathogenic mutations in these genes also are associated with improved outcomes must be explored. Preclinical models with ERCC2 and ERCC3 heterozygous knockouts show a hypomorphic functionality when exposed to DNA damaging agents, supporting a plausible mechanism for sensitivity to platinum therapies. ${ }^{23,25} \mathrm{Al}-$ though tumor MMR deficiency predicts response to PD-1 blockade in other solid tumors, to date, no large studies correlating MMR deficiency and response to PD-1 or PD-L1 blockade have included patients with UC. ${ }^{11}$ In this study, all patients with germline MMR mutations had MSI-H or MMRdeficient tumors, and 3 of 4 patients with Lynch syndrome had complete responses to immunotherapy after they experienced progression on chemotherapy. ${ }^{11,42}$ Our findings suggest that germline DDR alterations should be included with somatic alterations when assessing for correlations between therapeutic benefit.

Finally, a quarter of patients with high-penetrance germline variants would not have been detected by guidelinesdirected testing. Identification of germline mutations in these patients may allow for enhanced screening and early detection of hereditary cancers in those families for whom testing would not have been undertaken. Several individuals became the index cases (first detected cancer) in their families, which then led to cascade testing of other family members. Interestingly, among those with a family history of UC or personal history of other cancers, there was no increased incidence of P/LP germline variants. This may be explained in part by incomplete information available to patients-for example, of 8 patients with Lynch syndrome, none reported a family history of bladder or UT cancer, but 4 did report relatives with possible kidney cancer or of unclear origin, which may reflect UT cancers. Analysis in a larger cohort also may reveal whether personal history of cancer is associated with presence of germline alterations.

This study had several limitations. It was retrospective in nature and had a limited sample size; its findings will require validation in other cohorts. Given the smaller number of identified patients with clinically annotated data, associations between clinical features and prevalence of mutations may be limited by numbers. The study was conducted at a comprehensive cancer center with regional referral patterns, so the patient population may differ from that in the general community. For example, the median age of diagnosis in the cohort was 63 years, compared with approximately 70 years in the United States, and there was under-representation of nonwhite patients. ${ }^{43}$ We did observe a lower prevalence of germline mutations in the anonymized cohort, in which germline results were not returned. Although physicians were not instructed to select patients according to suspicion of an inherited syndrome, individuals consenting to return of germline results may 
have be more motivated to do so because of family history. We performed targeted exome sequencing of known cancerpredisposition genes; agnostic whole-exome sequencing could yield associations among novel genes or variants and risk of UC. $\mathrm{LOH}$ analysis was exploratory and was not corrected for possible increased background $\mathrm{LOH}$ in those genes, which also merits more study in larger cohorts.

This study demonstrates that germline mutations in patients with UC occur predominantly in DDR genes, with

\section{AFFILIATION}

${ }^{1}$ Memorial Sloan Kettering Cancer Center, New York, NY

\section{CORRESPONDING AUTHOR}

Maria I. Carlo, MD, 353 East 68th St, New York, NY 10065; e-mail: carlom@mskcc.org.

\section{EQUAL CONTRIBUTION}

D.F.B. and K.O. contributed equally to this work.

\section{PRIOR PRESENTATION}

Presented at the 2018 Genitourinary Cancers Symposium, San Francisco, CA, February 8-10, 2018, and American Society of Clinical Oncology 2017 Annual Meeting, Chicago, IL, June 2-6, 2019.

\section{SUPPORT}

Supported by the Bladder Specialized Program of Research Excellence grant No. P50 CA221745-01A1 from the National Cancer Institute, The Robert and Kate Niehaus Center for Inherited Cancer Genomics at Memorial Sloan Kettering Cancer Center, the Marie-Josée and Henry R. Kravis Center for Molecular Oncology, the Andrew Sabin Cancer Research Fund, the Carmel Family Cancer Research Fund, and Cancer Center Support Grant No. P30 CA008748-50.

\section{AUTHORS' DISCLOSURES OF POTENTIAL CONFLICTS OF INTEREST AND DATA AVAILABILITY STATEMENT}

Disclosures provided by the authors and data availability statement (if applicable) are available with this article at DOI https://doi.org/10.1200/ JCO.19.01395. increased frequency of BRCA2 and MSH2. Traditional criteria to identify those at risk for hereditary syndromes only identified a fraction of patients. There is potential value of expanded germline analysis in UC, particularly in patients of young age at diagnosis and those with UT tumors. The genes found to be mutated were associated with increased risk for cancers other than UC; thus, their identification likely will have substantial implications for directed cancer screening in patients and their families.

\section{AUTHOR CONTRIBUTIONS}

Conception and design: Maria I. Carlo, Vignesh Ravichandran, A. Ari Hakimi, Guido Dalbagni, Samuel A. Funt, David B. Solit, Jonathan E. Rosenberg, Mark E. Robson, Joseph Vijai, Dean F. Bajorin, Kenneth Offit Collection and assembly of data: Maria I. Carlo, Vignesh Ravichandran, Chaitanya Bandlamudi, Yelena Kemel, Joshua Chaim, Zarina Fnu, Angela G. Arnold, Aliya Khurram, Kaitlyn Tkachuk, Catharine K. Cipolla, Ashley Regazzi, Hikmat Al-Ahmadie, Michael F. Walsh, Min-Yuen Teo, Samuel A. Funt, Bernard H. Bochner, David B. Solit, Liying Zhang, Jonathan E. Rosenberg, Barry S. Taylor, Mark E. Robson, Michael F. Berger, Joseph Vijai, Dean F. Bajorin, Kenneth Offit

Administrative support: Aliya Khurram, Catharine K. Cipolla, Ashley Regazzi

Data analysis and interpretation: Maria I. Carlo, Vignesh Ravichandran, Preethi Srinavasan, Chaitanya Bandlamudi, Yelena Kemel, Ozge CeyhanBirsoy, Semanti Mukherjee, Diana Mandelker, Joshua Chaim, Andrea Knezevic, Satshil Rana, Kelsey Breen, Hikmat Al-Ahmadie, Karen A. Cadoo, Samuel A. Funt, Jonathan A. Coleman, Bernard H. Bochner, Gopa lyer, David B. Solit, Zsofia K. Stadler, Liying Zhang, Jonathan E. Rosenberg, Mark E. Robson, Michael F. Berger, Joseph Vijai, Dean F. Bajorin, Kenneth Offit

Provision of study material or patients: Guido Dalbagni, Min-Yuen Teo, Bernard H. Bochner, David B. Solit, Liying Zhang, Jonathan E. Rosenberg, Kenneth Offit

Administrative support: David B. Solit, Dean F. Bajorin, Kenneth Offit Financial support: David B. Solit, Kenneth Offit

Manuscript writing: All authors

Final approval of manuscript: All authors

Accountable for all aspects of the work: All authors

\section{REFERENCES}

1. Mucci LA, Hjelmborg JB, Harris JR, et al: Familial risk and heritability of cancer among twins in Nordic countries. JAMA 315:68-76, 2016

2. Kramer AA, Graham S, Burnett WS, et al: Familial aggregation of bladder cancer stratified by smoking status. Epidemiology 2:145-148, 1991

3. Lin J, Spitz MR, Dinney CP, et al: Bladder cancer risk as modified by family history and smoking. Cancer 107:705-711, 2006

4. Lynch HT, Walzak MP, Fried R, et al: Familial factors in bladder carcinoma. J Urol 122:458-461, 1979

5. Mahboubi AO, Ahlvin RC, Mahboubi EO: Familial aggregation of urothelial carcinoma. J Urol 126:691-692, 1981

6. McCullough DL, Lamma DL, McLaughlin AP III, et al: Familial transitional cell carcinoma of the bladder. J Urol 113:629-635, 1975

7. Joost $\mathrm{P}$, Therkildsen $\mathrm{C}$, Dominguez-Valentin $\mathrm{M}$, et al: Urinary tract cancer in Lynch syndrome: Increased risk in carriers of $M S H 2$ mutations. Urology 86 : 1212-1217, 2015

8. van der Post RS, Kiemeney LA, Ligtenberg MJ, et al: Risk of urothelial bladder cancer in Lynch syndrome is increased, in particular among MSH2 mutation carriers. J Med Genet 47:464-470, 2010

9. Robson M, Im SA, Senkus E, et al: Olaparib for metastatic breast cancer in patients with a germline BRCA mutation. N Engl J Med 377:523-533, 2017

10. Mateo J, Carreira S, Sandhu S, et al: DNA-repair defects and olaparib in metastatic prostate cancer. N Engl J Med 373:1697-1708, 2015

11. Le DT, Durham JN, Smith KN, et al: Mismatch repair deficiency predicts response of solid tumors to PD-1 blockade. Science 357:409-413, 2017

12. Plimack ER, Dunbrack RL, Brennan TA, et al: Defects in DNA repair genes predict response to neoadjuvant cisplatin-based chemotherapy in muscle-invasive bladder cancer. Eur Urol 68:959-967, 2015

13. Van Allen EM, Mouw KW, Kim P, et al: Somatic ERCC2 mutations correlate with cisplatin sensitivity in muscle-invasive urothelial carcinoma. Cancer Discov 4: $1140-1153,2014$ 
14. Teo MY, Seier K, Ostrovnaya I, et al: Alterations in DNA damage response and repair genes as potential marker of clinical benefit from PD-1/PD-L1 blockade in advanced urothelial cancers. J Clin Oncol 36:1685-1694, 2018

15. Schrader KA, Cheng DT, Joseph V, et al: Germline variants in targeted tumor sequencing using matched normal DNA. JAMA Oncol 2:104-111, 2016

16. Mandelker D, Zhang L, Kemel $\mathrm{Y}$, et al: Mutation detection in patients with advanced cancer by universal sequencing of cancer-related genes in tumor and normal DNA vs guideline-based germline testing. JAMA 318:825-835, 2017

17. Howlader N, Noone AM, Krapcho M (eds): SEER Cancer Statistics Review, 1975-2016, Bethesda, MD, National Cancer Institute. https://seer.cancer.gov/csr/ 1975_2016/

18. Cheng DT, Mitchell TN, Zehir A, et al: Memorial Sloan Kettering-integrated mutation profiling of actionable cancer targets (MSK-IMPACT): A hybridization capture-based next-generation sequencing clinical assay for solid tumor molecular oncology. J Mol Diagn 17:251-264, 2015

19. Zehir A, Benayed R, Shah RH, et al: Mutational landscape of metastatic cancer revealed from prospective clinical sequencing of 10,000 patients. Nat Med 23: 703-713, 2017

20. Richards S, Aziz N, Bale S, et al: Standards and guidelines for the interpretation of sequence variants: A joint consensus recommendation of the American College of Medical Genetics and Genomics and the Association for Molecular Pathology. Genet Med 17:405-424, 2015

21. Ravichandran V, Shameer Z, Kemel Y, et al: Toward automation of germline variant curation in clinical cancer genetics. Genet Med 21:2116-2125, 2019

22. Tung N, Domchek SM, Stadler Z, et al: Counselling framework for moderate-penetrance cancer-susceptibility mutations. Nat Rev Clin Oncol 13:581-588, 2016

23. Vijai J, Topka S, Villano D, et al: A Recurrent ERCC3 truncating mutation confers moderate risk for breast cancer. Cancer Discov 6:1267-1275, 2016

24. Shen R, Seshan VE: FACETS: Allele-specific copy number and clonal heterogeneity analysis tool for high-throughput DNA sequencing. Nucleic Acids Res 44: e131, 2016

25. Teo MY, Bambury RM, Zabor EC, et al: DNA damage response and repair gene alterations are associated with improved survival in patients with platinumtreated advanced urothelial carcinoma. Clin Cancer Res 23:3610-3618, 2017

26. National Comprehensive Cancer Network: Guidelines: Genetic/familial high-risk assessment—breast and ovarian, 2019. https://www.nccn.org/professionals/ physician_gls/pdf/genetics_screening.pdf

27. National Comprehensive Cancer Network: Guidelines: Genetic/familial high-risk assessment—Colorectal, 2018. https://www.nccn.org/professionals/ physician_gls/pdf/genetics_colon.pdf

28. Murta-Nascimento C, Silverman DT, Kogevinas M, et al: Risk of bladder cancer associated with family history of cancer: Do low-penetrance polymorphisms account for the increase in risk? Cancer Epidemiol Biomarkers Prev 16:1595-1600, 2007

29. PIna K, Hemminki K: Familial bladder cancer in the National Swedish Family Cancer Database. J Urol 166:2129-2133, 2001

30. Vasen HF, Stormorken A, Menko FH, et al: MSH2 mutation carriers are at higher risk of cancer than MLH1 mutation carriers: A study of hereditary nonpolyposis colorectal cancer families. J Clin Oncol 19:4074-4080, 2001

31. Aarnio M, Sankila R, Pukkala E, et al: Cancer risk in mutation carriers of DNA-mismatch-repair genes. Int J Cancer 81:214-218, 1999

32. Harper HL, McKenney JK, Heald B, et al: Upper tract urothelial carcinomas: Frequency of association with mismatch repair protein loss and lynch syndrome. Mod Pathol 30:146-156, 2017

33. Audenet $\mathrm{F}$, Isharwal $\mathrm{S}$, Cha EK, et al: Clonal relatedness and mutational differences between upper tract and bladder urothelial carcinoma. Clin Cancer Res 25: 967-976, 2018

34. Kwon JS, Scott JL, Gilks CB, et al: Testing women with endometrial cancer to detect Lynch syndrome. J Clin Oncol 29:2247-2252, 2011

35. Latham A, Srinivasan P, Kemel Y, et al: Microsatellite instability is associated with the presence of Lynch syndrome pan-cancer. J Clin Oncol 37:286-295, 2019

36. Yap KL, Kiyotani K, Tamura K, et al: Whole-exome sequencing of muscle-invasive bladder cancer identifies recurrent mutations of UNC5C and prognostic importance of DNA repair gene mutations on survival. Clin Cancer Res 20:6605-6617, 2014

37. Robertson AG, Kim J, Al-Ahmadie H, et al: Comprehensive molecular characterization of muscle-invasive bladder cancer. Cell 171:540-556.e25, 2017

38. Stern MC, Lin J, Figueroa JD, et al: Polymorphisms in DNA repair genes, smoking, and bladder cancer risk: Findings from the international consortium of bladder cancer. Cancer Res 69:6857-6864, 2009

39. Cancer Genome Atlas Research Network: Comprehensive molecular characterization of urothelial bladder carcinoma. Nature 507:315-322, 2014

40. Liu D, Plimack ER, Hoffman-Censits J, et al: Clinical validation of chemotherapy response biomarker ERCC2 in muscle-invasive urothelial bladder carcinoma. JAMA Oncol 2:1094-1096, 2016

41. Teo MY, Seier K, Ostrovnaya I, et al: Alterations in DNA damage response and repair genes as potential marker of clinical benefit from PD-1/PD-L1 blockade in advanced urothelial cancers. J Clin Oncol 36:1685-1694, 2018

42. Le DT, Uram JN, Wang H, et al: PD-1 blockade in tumors with mismatch-repair deficiency. N Engl J Med 372:2509-2520, 2015

43. Scosyrev E, Noyes K, Feng C, et al: Sex and racial differences in bladder cancer presentation and mortality in the US. Cancer 115:68-74, 2009 


\section{Cancer Susceptibility Mutations in Patients With Urothelial Malignancies}

The following represents disclosure information provided by authors of this manuscript. All relationships are considered compensated unless otherwise noted. Relationships are self-held unless noted. I = Immediate Family Member, Inst = My Institution. Relationships may not relate to the subject matter of this manuscript. For more information about ASCO's conflict of interest policy, please refer to www.asco.org/rwc or ascopubs.org/journal/jco/site/ifc.

Open Payments is a public database containing information reported by companies about payments made to US-licensed physicians (Open Payments).

Maria I. Carlo

Consulting or Advisory Role: Pfizer

Other Relationship: Prostate Cancer Foundation, Robert Wood Johnson Foundation

Semanti Mukherjee

Stock and Other Ownership Interests: Regeneron

Catharine K. Cipolla

Stock and Other Ownership Interests: Roche

Travel, Accommodations, Expenses: Flatiron Health

Hikmat Al-Ahmadie

Consulting or Advisory Role: Bristol-Myers Squibb, EMD Serono, AstraZeneca/ Medlmmune

Karen A. Cadoo

Research Funding: AstraZeneca (Inst)

Research Funding: Syndax (Inst)

Travel, Accommodations, Expenses: AstraZeneca

Min-Yuen Teo

Research Funding: Bristol-Myers Squibb, Clovis Oncology

Samuel A. Funt

Stock and Other Ownership Interests: Kite Pharma, Urogen Pharma (I), Hubble (I), Second Science, Allogene Therapeutics, Neogene Therapeutics, Kronos Bio (I), Vida Ventures (I)

Consulting or Advisory Role: AstraZeneca (Inst), Medlmmune (Inst)

Research Funding: Genentech (Inst), Roche (Inst), AstraZeneca (Inst), Decibe

Therapeutics (Inst)

Travel, Accommodations, Expenses: Bristol-Myers Squibb, AstraZeneca,

Medlmmune

Jonathan A. Coleman

Travel, Accommodations, Expenses: Digital Angiography Reading Center (I) Other Relationship: Steba Biotech

Bernard H. Bochner

Honoraria: Genentech, Roche

Consulting or Advisory Role: Genentech, Roche, Olympus

Gopa lyer

Consulting or Advisory Role: Bayer, Janssen, Mirati Therapeutics

Research Funding: Mirati Therapeutics (Inst), Novartis (Inst), Debiopharm Group (Inst), Bayer (Inst)

David B. Solit

Stock and Other Ownership Interests: LoxO

Consulting or Advisory Role: Pfizer, Loxo, Illumina, Intezyne Technologies,

Vivideon Therapeutics, Lilly Oncology

Travel, Accommodations, Expenses: Merck KGaA

\section{Zsofia K. Stadler}

Consulting or Advisory Role: Allergan (I), Genentech (I), Roche (I), Regeneron (I), Optos (I), Adverum (I), Biomarin (I), Alimera Sciences (I), Novartis (I), Spark Therapeutics (I), Fortress Biotech (I), Regenxbio (I)

\section{Liying Zhang}

Employment: Shanghai Genome Center (I)

Leadership: Shanghai Genome Center (I)

Stock and Other Ownership Interests: Shanghai Genome Center (I)

Honoraria: Future Technology Research, BGI, Illumina, Roche Diagnostics Asia

Pacific

Travel, Accommodations, Expenses: Shanghai Genome Center (I), Roche

Diagnostics Asia Pacific

\section{Jonathan E. Rosenberg}

Stock and Other Ownership Interests: Merck, Illumina

Honoraria: UpToDate, Bristol-Myers Squibb, AstraZeneca, Medscape, Vindico, Peerview, Chugai Pharma, Research to Practice, Intellisphere, Clinical Care Options, Clinical Mind

Consulting or Advisory Role: Lilly, Merck, Agensys, Roche, Genentech, Sanofi, AstraZeneca, Medimmune, Bristol-Myers Squibb, EMD Serono, Seattle

Genetics, Bayer, Inovio Pharmaceuticals, BioClin Therapeutics, QED

Therapeutics, Adicet Bio, Sensei Biotherapeutics, Fortress Biotech,

Pharmacyclics, Western Oncolytics, GlaxoSmithKline, Janssen Oncology, Astellas Pharma

Research Funding: Oncogenex (Inst), Agensys (Inst), Mirati Therapeutics (Inst), Novartis (Inst), Viralytics (Inst), Genentech (Inst), Roche (Inst), Incyte (Inst), Seattle Genetics (Inst), Bayer (Inst), AstraZeneca (Inst), QED Therapeutics (Inst), Astellas Pharma (Inst)

Patents, Royalties, Other Intellectual Property: Predictor of platinum sensitivity (Inst)

Travel, Accommodations, Expenses: Genentech, Roche, Bristol-Myers Squibb

Barry S. Taylor

Consulting or Advisory Role: Boehringer Ingelheim

Research Funding: Genentech

Mark E. Robson

Honoraria: AstraZeneca

Consulting or Advisory Role: McKesson, AstraZeneca

Research Funding: AstraZeneca (Inst), Myriad Genetics (Inst), InVitae (Inst), AbbVie (Inst), Tesaro (Inst), Medivation (Inst)

Travel, Accommodations, Expenses: AstraZeneca, Pfizer

Other Relationship: Research to Practice, Clinical Care Options, Physician Education Resource

Uncompensated Relationships: Merck, Pfizer, Daiichi Sankyo

Open Payments Link: https://openpaymentsdata.cms.gov/physician/612669/ summary

Michael F. Berger

Consulting or Advisory Role: Roche

Research Funding: Grail

Joseph Vijai

Patents, Royalties, Other Intellectual Property: Title: Diagnosis \& treatment of ERCC3-mutant cancer; Inventors: Vijai Joseph, Sabine Topka, Kenneth Offit; US National Stage Patent Application No.: 16/493,214; Filing Date: September 11, 2019 (Inst)

Dean F. Bajorin

Honoraria: Merck Sharp \& Dohme

Consulting or Advisory Role: Bristol-Myers Squibb, Novartis, Roche, Genentech, Merck, Lilly, Fidia Farmaceutici, Urogen Pharma, Pfizer, EMD Serono

Research Funding: Novartis (Inst), Genentech (Inst), Roche (Inst), Merck (Inst), Bristol-Myers Squibb (Inst), AstraZeneca (Inst), Astellas Pharma (Inst), Seattle Genetics (Inst), Astellas (Inst)

Travel, Accommodations, Expenses: Roche, Genentech, Merck, Bristol-Myers Squibb, Lilly, Urogen Pharma

No other potential conflicts of interest were reported. 

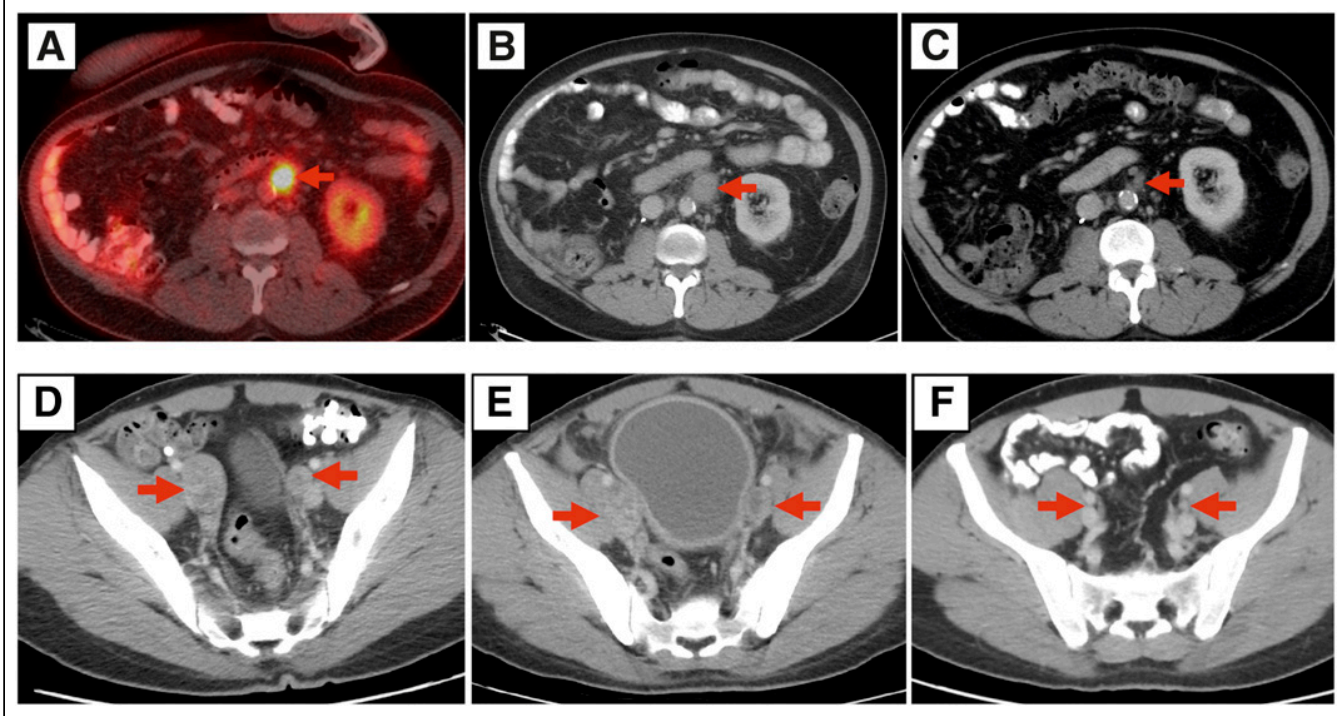

FIG A1. Response to chemotherapy and immunotherapy in two patients with Lynch syndrome. (A) 18Fluorodeoxyglucose positron emission tomography/computer tomography (PET/CT) image reveals a left para-aortic lymph node measuring $1.9 \mathrm{~cm}$ in largest dimension (red arrow) before initiation of paclitaxel. (B) Post-treatment CT after six infusions of paclitaxel shows enlargement of lymph node to $2.4 \mathrm{~cm}$. (C) Post-treatment CT after six infusions of atezolizumab shows reduction in lymph node size to $0.9 \mathrm{~cm}$, considered complete response by RECIST v $1.1 \mathrm{criteria}$. (D) CT image in another patient reveals right and left external iliac lymph nodes measuring $2.8 \mathrm{~cm}$ and $2.3 \mathrm{~cm}$ in largest dimensions, respectively (red arrows), before initiation of platinum-based chemotherapy. (E) Post-treatment CT after three cycles of platinum-based therapy shows right lymph node now to $2.7 \mathrm{~cm}$ and left to $3.2 \mathrm{~cm}$. Treatment with chemotherapy was stopped, and the patient proceeded to treatment with a programmed death ligand 1 (PDL-1) inhibitor. (F) Post-treatment CT after 24 infusions of PDL-1 inhibitor shows disappearance of right lymph node and reduction of left lymph node to $0.6 \mathrm{~cm}$. After 26 months on immune therapy, the patient proceeded to radical cystectomy with lymph node resection. Pathology review showed a complete pathologic response without residual carcinoma. 
TABLE A1. Genes on MSK-IMPACT and Syndromes Associated With Germline Mutations

\begin{tabular}{ll} 
Gene & \multicolumn{1}{c}{ Syndrome } \\
\hline ABL1 & \\
\hline ACVR1 & \\
\hline AKT1 & \\
\hline AKT2 & \\
\hline AKT3 & \\
\hline ALK & Familial neuroblastoma \\
\hline ALOX12B & \\
\hline AMER1 & \\
\hline ANKRD11 & \\
\hline APC & \\
\hline AR & \\
\hline$A R A F$ & \\
\hline$A R I D 1 A$ & \\
\hline$A R I D 1 B$ & \\
\hline$A R I D 2$ & \\
\hline$A R I D 5 B$ &
\end{tabular}

\begin{tabular}{l}
$A S X L 1$ \\
\hline$A S X L 2$
\end{tabular}

\begin{tabular}{ll}
\hline $\boldsymbol{A T M}$ & Ataxia-telangiectasia; ATM-related cancer risk \\
\hline ATR & \\
\hline ATRX & \\
\hline AURKA
\end{tabular}

\begin{tabular}{l}
$A \cup R K B$ \\
\hline$A X I N 1$
\end{tabular}

\begin{tabular}{l}
\hline$A X I N 2$ \\
\hline$A X L$ \\
\hline$B 2 M$ \\
\hline$B A B A M 1$
\end{tabular}

\begin{tabular}{ll}
\hline BAP1 & Mesothelioma, uveal melanoma, RCC \\
\hline BARD1 & Hereditary breast and ovarian cancer syndrome \\
\hline$B B C 3$ & \\
\hline$B C L 10$ & \\
\hline$B C L 2$ & \\
\hline$B C L 2 L 11$ & \\
\hline$B C L 2 L 1$ & \\
\hline$B C L 6$ & \\
\hline$B C O R$ & Bloom syndrome \\
\hline$B I R C 3$ & Juvenile polyposis syndrome \\
\hline BLM & \\
\hline BMPR1A & Hereditary breast and ovarian cancer syndrome \\
\hline$B R A F$ & (continued in next column) \\
\hline BRCA1 & \\
\hline
\end{tabular}

TABLE A1. Genes on MSK-IMPACT and Syndromes Associated With Germline Mutations (continued)

\begin{tabular}{ll} 
Gene & \multicolumn{1}{c}{ Syndrome } \\
\hline BRCA2 & $\begin{array}{c}\text { Hereditary breast and ovarian cancer syndrome; } \\
\text { Fanconi anemia }\end{array}$ \\
\hline BRD4 & BRIP1-related cancer; Fanconi anemia \\
\hline BRIP1 & \\
\hline BTK & \\
\hline KNSTRN & \\
\hline CALR & \\
\hline CARD11 & \\
\hline CARM1 & \\
\hline CASP8 & \\
\hline CBFB & \\
\hline CBL & \\
\hline CCND1 & \\
\hline CCND2 \\
\hline CCND3 \\
\hline CCNE1 \\
\hline CD274 \\
\hline CD276 \\
\hline CD79A \\
\hline CD79B \\
\hline CDC42 \\
\hline CDC73 \\
\hline COH1 \\
\hline
\end{tabular}

\begin{tabular}{ll}
\hline $\mathbf{C D H 1}$ & Hereditary diffuse gastric cancer \\
\hline CDK12 & \\
\hline $\mathbf{C D K 4}$ & Familial cutaneous melanoma
\end{tabular}

\begin{tabular}{l}
\hline CDK6 \\
\hline CDK8 \\
\hline CDKN1A \\
\hline CDKN1B \\
\hline CDKN2A Familial cutaneous melanoma \\
\hline CDKN2B \\
\hline CDKN2C \\
\hline CEBPA \\
\hline CENPA \\
\hline CHEK1 \\
\hline CHEK2 \\
\hline CIC \\
\hline CREBBP \\
\hline CRKL \\
\hline CRLF2 \\
\hline CSDE1 \\
\hline CSF1R \\
\hline CSF3R \\
\hline
\end{tabular}

(continued on following page) 
TABLE A1. Genes on MSK-IMPACT and Syndromes Associated With Germline Mutations (continued)

\begin{tabular}{|c|c|}
\hline Gene & Syndrome \\
\hline CTCF & \\
\hline CTLA4 & \\
\hline CTNNB1 & \\
\hline CUL3 & \\
\hline CXCR4 & \\
\hline$C Y L D$ & \\
\hline CYSLTR2 & \\
\hline$D A X X$ & \\
\hline DCUN1D1 & \\
\hline$D D R 2$ & \\
\hline DICER1 & DICER1-related disorders \\
\hline DIS3 & \\
\hline DNAJB1 & \\
\hline DNMT1 & \\
\hline DNMT3A & \\
\hline DNMT3B & \\
\hline DOT1L & \\
\hline DROSHA & \\
\hline DUSP4 & \\
\hline E2F3 & \\
\hline EED & \\
\hline EGFL7 & \\
\hline EGFR & Familial lung cancer \\
\hline EIF1AX & \\
\hline AGO2 & \\
\hline EIF4A2 & \\
\hline EIF4E & \\
\hline ELF3 & \\
\hline EP300 & \\
\hline EPAS1 & \\
\hline EPCAM & Lynch syndrome \\
\hline EPHA3 & \\
\hline EPHA5 & \\
\hline EPHA7 & \\
\hline EPHB1 & \\
\hline ERBB2 & \\
\hline ERBB3 & \\
\hline ERBB4 & \\
\hline ERCC2 & Xeroderma pigmentosum \\
\hline ERCC3 & $\begin{array}{l}\text { Xeroderma pigmentosum/ Hereditary breast cancer } \\
\text { syndrome }\end{array}$ \\
\hline ERCC4 & \\
\hline ERCC5 & \\
\hline
\end{tabular}

(continued in next column)
TABLE A1. Genes on MSK-IMPACT and Syndromes Associated With Germline Mutations (continued)

\begin{tabular}{ll} 
Gene & Syndrome \\
\hline$E R F$ & \\
\hline$E R G$ & \\
\hline$E R R F I 1$ \\
\hline$E S R 1$ \\
\hline$E T V 1$ \\
\hline$E T V 6$ \\
\hline$E Z H 1$ \\
\hline$E Z H 2$
\end{tabular}

\begin{tabular}{l}
\hline FAM175A Hereditary breast cancer syndrome \\
\hline FAM46C \\
\hline FAM58A \\
\hline FANCA \\
\hline FANCC \\
\hline FAT1 \\
\hline FBXW7 \\
\hline FGF19 \\
\hline FGF3 \\
\hline FGF4 \\
\hline FGFR1 \\
\hline FGFR2 \\
\hline FGFR3 \\
\hline FGFR4
\end{tabular}

\begin{tabular}{ll}
\hline $\boldsymbol{F H}$ & Hereditary leiomyomatosis and renal cell cancer \\
\hline $\boldsymbol{F L C N}$ & Birt-Hogg-Dubé syndrome \\
\hline$F L T 1$ & \\
\hline
\end{tabular}

FLT3

FLT4

FOXA1

FOXL2

FOXO1

FOXP1

FUBP1

FYN

GATA1

GATA2 Familial MDS-AML

GATA3

GLII

GNA11

GNAQ

GNAS

GPS2

GRIN2A

GSK3B

(continued on following page) 
TABLE A1. Genes on MSK-IMPACT and Syndromes Associated With Germline Mutations (continued)

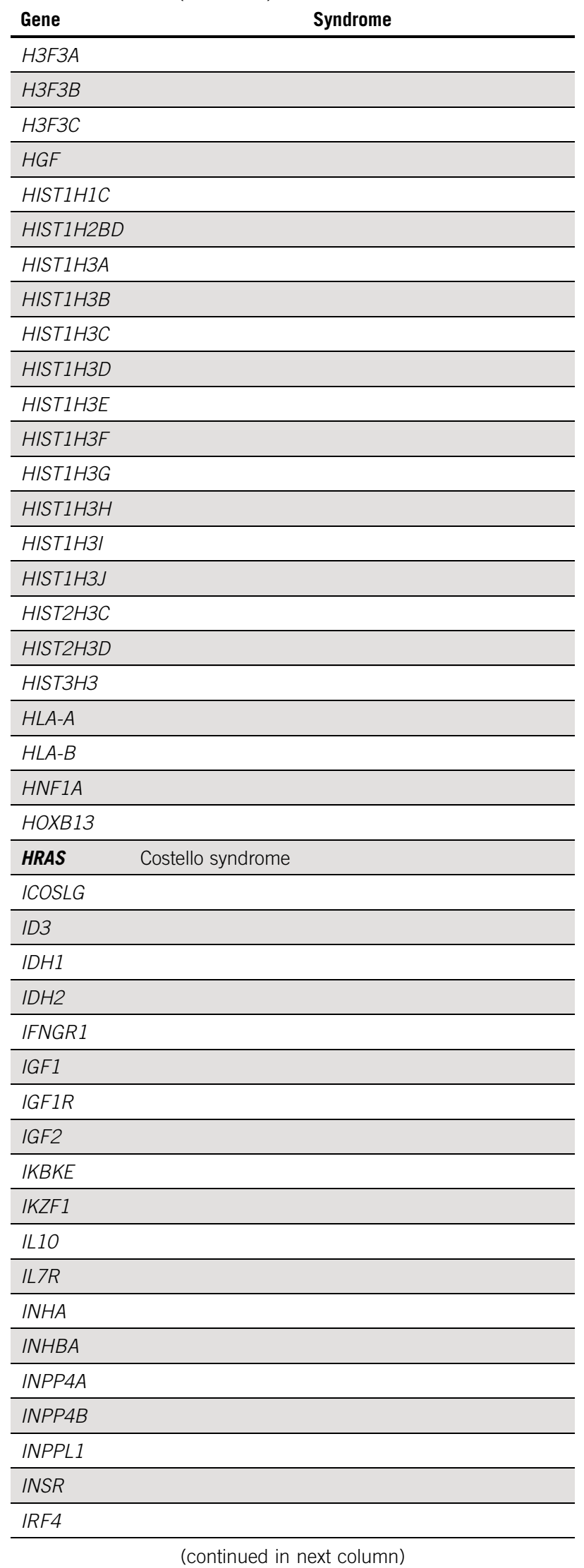

TABLE A1. Genes on MSK-IMPACT and Syndromes Associated With Germline Mutations (continued)

\begin{tabular}{ll} 
Gene & \multicolumn{1}{c}{ Syndrome } \\
\hline$I R S 1$ & \\
\hline$I R S 2$ & \\
\hline JAK1 & \\
\hline JAK2 & Familial thrombocytosis \\
\hline JAK3 & \\
\hline JUN & \\
\hline KDM5A & \\
\hline KDM5C & \\
\hline KDM6A & \\
\hline KDR & \\
\hline KEAP1 & \\
\hline KIT & Hereditary gastrointestinal stromal tumors \\
\hline KLF4 & \\
\hline KRAS & Noonan syndrome
\end{tabular}

\begin{tabular}{l}
\hline LATS1 \\
\hline LATS2 \\
\hline LMO1 \\
\hline LYN \\
\hline MALT1 \\
\hline MAP2K1 \\
\hline MAP2K2 \\
\hline MAP2K4 \\
\hline MAP3K13 \\
\hline MAP3K14 \\
\hline MAP3K1 \\
\hline MAPK1 \\
\hline MAPK3 \\
\hline MAPKAP1 \\
\hline MAX
\end{tabular}

\section{MCL1}

$M D C 1$

MDM2

MDM4

MED12

MEF2B

MEN1 Multiple endocrine neoplasia, type 1

MET Hereditary papillary renal carcinoma

$M G A$

MITF Familial melanoma and renal cell carcinoma

MLH1 Lynch syndrome

MLL2

MLL3

(continued on following page) 
TABLE A1. Genes on MSK-IMPACT and Syndromes Associated With Germline Mutations (continued)

\begin{tabular}{|c|c|}
\hline Gene & Syndrome \\
\hline \multicolumn{2}{|l|}{ MLL4 } \\
\hline \multicolumn{2}{|l|}{$M L L$} \\
\hline \multicolumn{2}{|l|}{$M P L$} \\
\hline MRE11A & $\begin{array}{l}\text { Ataxia-telangiectasia-like disorder } \\
\text { (recessive); breast cancer }\end{array}$ \\
\hline MSH2 & Lynch syndrome \\
\hline \multicolumn{2}{|l|}{ MSH3 } \\
\hline MSH6 & Lynch syndrome \\
\hline \multicolumn{2}{|l|}{$M S / 1$} \\
\hline \multicolumn{2}{|l|}{ MSI2 } \\
\hline \multicolumn{2}{|l|}{ MST1 } \\
\hline \multicolumn{2}{|l|}{ MST1R } \\
\hline \multicolumn{2}{|l|}{ MTOR } \\
\hline MUTYH & MUTYH-associated polyposis \\
\hline \multicolumn{2}{|l|}{ MYC } \\
\hline \multicolumn{2}{|l|}{ MYCL1 } \\
\hline \multicolumn{2}{|l|}{ MYCN } \\
\hline \multicolumn{2}{|l|}{ MYD88 } \\
\hline \multicolumn{2}{|l|}{ MYOD1 } \\
\hline NBN & $\begin{array}{l}\text { Nijmegen breakage syndrome; NBN-related cancer } \\
\text { risk }\end{array}$ \\
\hline \multicolumn{2}{|l|}{ NCOA3 } \\
\hline \multicolumn{2}{|l|}{ NCOR1 } \\
\hline \multicolumn{2}{|l|}{ NEGR1 } \\
\hline NF1 & Neurofibromatosis, type 1 \\
\hline NF2 & Neurofibromatosis, type 2 \\
\hline \multicolumn{2}{|l|}{ NFE2L2 } \\
\hline \multicolumn{2}{|l|}{ NFKBIA } \\
\hline \multicolumn{2}{|l|}{ NKX2-1 } \\
\hline \multicolumn{2}{|l|}{ NKX3-1 } \\
\hline \multicolumn{2}{|l|}{ NOTCH1 } \\
\hline \multicolumn{2}{|l|}{ NOTCH2 } \\
\hline \multicolumn{2}{|l|}{ NOTCH3 } \\
\hline \multicolumn{2}{|l|}{ NOTCH4 } \\
\hline \multicolumn{2}{|l|}{ NPM1 } \\
\hline NRAS & Autoimmune lymphoproliferative syndrome \\
\hline \multicolumn{2}{|l|}{ NSD1 } \\
\hline NTHL1 & \\
\hline NTRK1 & \\
\hline NTRK2 & \\
\hline NTRK3 & \\
\hline NUF2 & \\
\hline NUP93 & \\
\hline
\end{tabular}

(continued in next column)
TABLE A1. Genes on MSK-IMPACT and Syndromes Associated With Germline Mutations (continued)

Gene

\section{Syndrome}

PAK1

PAK7

PALB2 PALB2-related cancer; Fanconi anemia

PARK2

PARP1

PAX5 B cell precursor acute lymphoblastic leukemia

PBRM1

PDCD1

PDCD1LG2

\begin{tabular}{ll}
\hline PDGFRA & Hereditary gastrointestinal stromal tumors \\
\hline PDGFRB & \\
\hline PDPK1 & \\
\hline$P G R$ &
\end{tabular}

\begin{tabular}{ll}
\hline PHOX2B & $\begin{array}{c}\text { Familial neuroblastoma; congenital central } \\
\text { hypoventilation syndrome }\end{array}$ \\
\hline
\end{tabular}

PIK3C2G

PIK3C3

PIK3CA

PIK3CB

PIK3CD

PIK3CG

PIK3RI

PIK3R2

PIK3R3

PIM1

PLCG2

PLK2

PMAIPI

PMS1

PMS2 Lynch syndrome

PNRC

POLD1

POLE Colorectal cancer and endometrial cancer

PPARG

$P P M 1 D$

PPP2R1A

PPP4R2

PPP6C

PRDM14

PRDM1

PREX2

PRKAR1A

PRKCI

(continued on following page) 
TABLE A1. Genes on MSK-IMPACT and Syndromes Associated With Germline Mutations (continued)

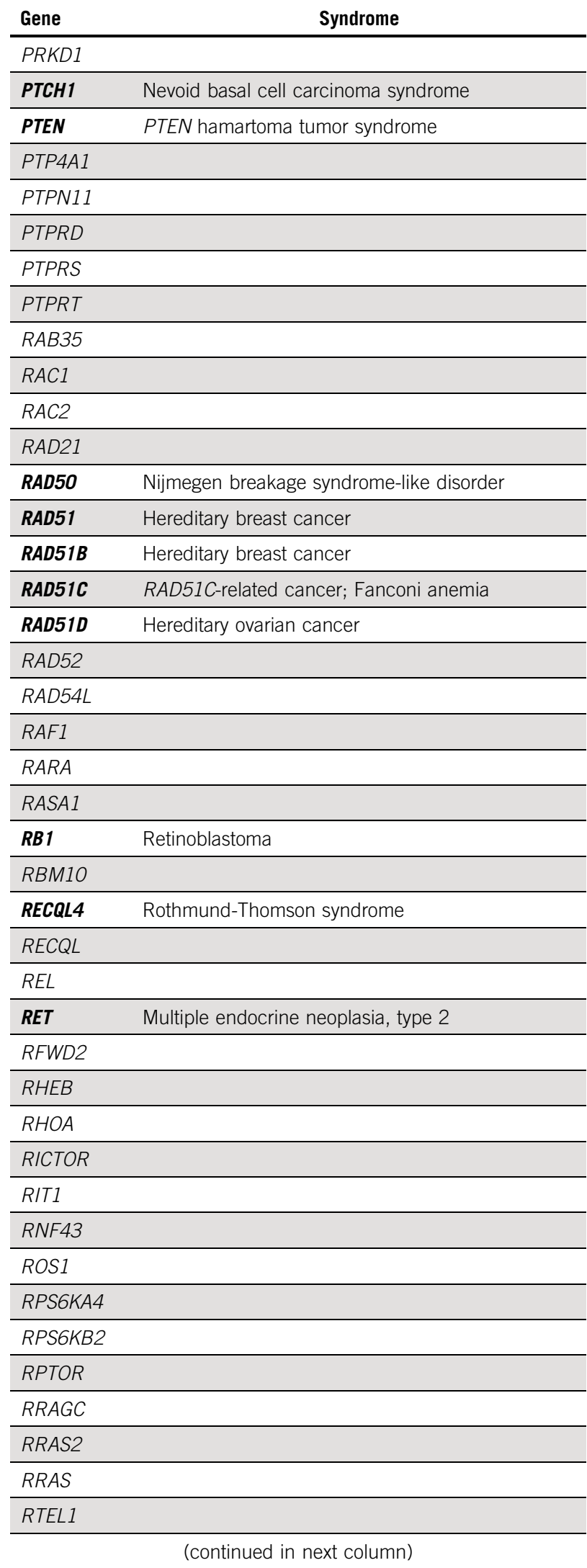

TABLE A1. Genes on MSK-IMPACT and Syndromes Associated With Germline Mutations (continued)

Gene Syndrome

RUNX1 Familial platelet disorder with predisposition to acute myelogenous leukemia

\begin{tabular}{lc}
\hline$R X R A$ & \\
\hline$R Y B P$ & $\begin{array}{c}\text { Hereditary paraganglioma-pheochromocytoma } \\
\text { syndromes }\end{array}$ \\
\hline SDHA & $\begin{array}{c}\text { Hereditary paraganglioma-pheochromocytoma } \\
\text { syndromes }\end{array}$ \\
\hline SDHAF2 & $\begin{array}{c}\text { Hereditary paraganglioma-pheochromocytoma } \\
\text { syndromes }\end{array}$ \\
\hline SDHB & $\begin{array}{c}\text { Hereditary paraganglioma-pheochromocytoma } \\
\text { syndromes }\end{array}$ \\
\hline SDHC & $\begin{array}{c}\text { Hereditary paraganglioma-pheochromocytoma } \\
\text { (PGL/PCC) syndromes }\end{array}$ \\
\hline SDHD & \\
\hline SESN1 & \\
\hline SESN2 & \\
\hline SESN3 & \\
\hline SETD2 & \\
\hline SETD8 & \\
\hline SF3B1 & \\
\hline SH2B3 & \\
\hline SH2D1A & \\
\hline SHOC2 & \\
\hline SHQ1 & \\
\hline SLX4 & \\
\hline SMAD2 & \\
\hline
\end{tabular}

SMAD2

SMAD3 Thoracic aortic aneurysms and aortic dissections

SMAD4 Juvenile polyposis syndrome

SMARCA4 Rhabdoid tumor predisposition syndrome type 2

SMARCB1 Rhabdoid tumor predisposition syndrome type 1

SMARCDI

SMO

SMYD3

SOCS1

SOS1

SOX17

SOX2

SOX9

SPEN

SPOP

SPREDI

$S R C$

SRSF2

STAG2

(continued on following page) 
TABLE A1. Genes on MSK-IMPACT and Syndromes Associated With Germline Mutations (continued)

\begin{tabular}{|c|c|}
\hline Gene & Syndrome \\
\hline \multicolumn{2}{|l|}{ STAT3 } \\
\hline \multicolumn{2}{|l|}{ STAT5A } \\
\hline \multicolumn{2}{|l|}{ STAT5B } \\
\hline STK11 & Peutz-Jeghers syndrome \\
\hline \multicolumn{2}{|l|}{ STK19 } \\
\hline \multicolumn{2}{|l|}{ STK4O } \\
\hline SUFU & Medulloblastoma \\
\hline \multicolumn{2}{|l|}{ SUZ12 } \\
\hline \multicolumn{2}{|l|}{ SYK } \\
\hline \multicolumn{2}{|l|}{ TAP1 } \\
\hline \multicolumn{2}{|l|}{ TAP2 } \\
\hline \multicolumn{2}{|l|}{ TBX3 } \\
\hline \multicolumn{2}{|l|}{ TCEB 1} \\
\hline \multicolumn{2}{|l|}{ TCF3 } \\
\hline \multicolumn{2}{|l|}{ TCF7L2 } \\
\hline \multicolumn{2}{|l|}{ TEK } \\
\hline TERT & Familial pulmonary fibrosis; dyskeratosis congenita \\
\hline \multicolumn{2}{|l|}{ TET1 } \\
\hline \multicolumn{2}{|l|}{ TET2 } \\
\hline TGFBR1 & Thoracic aortic aneurysms and aortic dissections \\
\hline TGFBR2 & Thoracic aortic aneurysms and aortic dissections \\
\hline TMEM127 & Familial pheochromocytoma syndrome \\
\hline \multicolumn{2}{|l|}{ TMPRSS2 } \\
\hline \multicolumn{2}{|l|}{ TNFAIP3 } \\
\hline \multicolumn{2}{|l|}{ TNFRSF14 } \\
\hline \multicolumn{2}{|l|}{ TOP1 } \\
\hline TP53 & Li-Fraumeni syndrome \\
\hline \multicolumn{2}{|l|}{ TP53BP1 } \\
\hline \multicolumn{2}{|l|}{ TP63 } \\
\hline \multicolumn{2}{|l|}{ TRAF2 } \\
\hline \multicolumn{2}{|l|}{ TRAF7 } \\
\hline TSC1 & Tuberous sclerosis complex \\
\hline TSC2 & Tuberous sclerosis complex \\
\hline \multicolumn{2}{|l|}{ TSHR } \\
\hline \multicolumn{2}{|l|}{ U2AF1 } \\
\hline \multicolumn{2}{|l|}{ UPF1 } \\
\hline VEGFA & \\
\hline VHL & $\begin{array}{l}\text { Von Hippel-Lindau syndrome; familial erythrocytosis, } \\
\text { type } 2\end{array}$ \\
\hline VTCN1 & \\
\hline WHSC1 & \\
\hline WHSC1L1 & \\
\hline & (continued in next column) \\
\hline
\end{tabular}

TABLE A1. Genes on MSK-IMPACT and Syndromes Associated With Germline Mutations (continued)

\begin{tabular}{ll} 
Gene & \multicolumn{1}{c}{ Syndrome } \\
\hline WT1 & $\begin{array}{c}\text { Wilms tumor-aniridia-genital anomalies-retardation } \\
\text { syndrome, Denys-Drash syndrome, Frasier } \\
\text { syndrome, and isolated Wilms tumor }\end{array}$ \\
\hline WWTR1 & \\
\hline XIAP & \\
\hline XPO1 & \\
\hline XRCC2 \\
\hline YAP1 \\
\hline YES1 \\
\hline ZFHX3 \\
\hline ZRSR2
\end{tabular}

NOTE. Genes in bold were included for germline analysis.

Abbreviations: MDS-AML, myelodysplastic syndrome/acute myeloid leukemia; RCC, renal cell carcinoma. 
TABLE A2. DDR Gene Panel

DDR Pathway

\begin{tabular}{lccccc}
\hline MMR & NER & HR & FA & Checkpoint & Other \\
\hline MLH1 & ERCC2 & BRCA1 & BRCA2 & ATM & POLE \\
\hline MSH2 & ERCC3 & MRE11A & BRIP1 & ATR & MUTYH \\
\hline MSH6 & ERCC4 & NBN & FANCA & CHEK1 & PARP1 \\
\hline PMS1 & ERCC5 & RAD50 & FANCC & CHEK2 & RECQL4 \\
\hline PMS2 & - & RAD51 & PALB2 & MDC1 & - \\
\hline- & - & RAD51B & RAD51C & - & - \\
\hline- & - & RAD51D & BLM & - & - \\
\hline- & - & RAD52 & - & - & - \\
\hline- & - & RAD54L & - & - & -
\end{tabular}

Abbreviations: DDR, DNA-damage repair; HR, homologous recombination; FA, Fanconi anemia; MMR, mismatch repair; NER, nucleotide excision repair.

TABLE A3. Ashkenazi Jewish and European Founder Mutations

\begin{tabular}{l}
\hline BRCA1 c.68_69delAG (p.Glu23Valfs $\left.{ }^{\star} 17\right)$ \\
\hline BRCA1 c.5266dupC (p.Gln1756Profs*74) \\
\hline BRCA2 c.5946delT (p.Ser1982Argfs ${ }^{\star 22) ~}$ \\
\hline CHEK2 c.1100delC (p.Thr367Metfs ${ }^{* 15)}$ \\
\hline CHEK2 c.1283C>T (p.Ser428Phe) \\
\hline APC c.3920T>A (p.Ile1307Lys) \\
\hline MUTYH c.1187G>A (p.Gly396Asp) \\
\hline MUTYH c. $536 A>G$ (p.Tyr179Cys) \\
\hline ERCC3 c.325C>T (p.Arg109X)
\end{tabular}


TABLE A4. Detail on Pathogenic/Likely Pathogenic Germline Variants

Study ID Gene

A1 APC $\quad$ c.3920T $>$ A

A2 $\quad A P C \quad$ C.3920T $>$ A

A3 APC C.3920T $>A$

\begin{tabular}{lll}
\hline A4 & APC & c.3920T $>$ A \\
\hline
\end{tabular}

$\begin{array}{lll}\text { A5 } & A P C & \text { C.3920T }>A\end{array}$

$\begin{array}{lll}\text { B1 } & \text { APC } & \text { c.3920T }>\text { A }\end{array}$

$\begin{array}{lll}\text { B164 APC } & \text { c.3920T }>\text { A }\end{array}$

$\begin{array}{lll}\text { B23 } A P C & \text { c.3920T }>\text { A }\end{array}$

$\begin{array}{lll}\text { A7 } & \text { ATM } & \text { C.5932G }>T\end{array}$

A8

$$
\text { A }
$$

A10$$
\text { A6 }
$$

$\begin{array}{lll}\text { A6 } & \text { APC } & \text { c.3920T }>A\end{array}$

A11 BRCA1 c.5319dupC

A21 CHEK2 C. $444+1 G>$ A

\begin{tabular}{lll}
\hline A12 & BRCA1 & c.116G $>$ A
\end{tabular}

A13 BRCA1 c.68_69delAG

$\begin{array}{lll}\text { B13 BRCA1 C.1687C }>\text { T } & \text {. }\end{array}$

B148 BRCA1 c.68_69delAG

B21 BRCA1 c.68_69delAG

$\begin{array}{lll}\text { B22 } & \text { BRCA1 } & \text { C.5074G }>C\end{array}$

A14 BRCA2 c.5799_5802delCCAA

\begin{tabular}{lll}
\hline A15 & BRCA2 & c.8537_8538delAG
\end{tabular}

$\begin{array}{lll}\text { A16 BRCA2 } & \text { c.1238delT }\end{array}$

$\begin{array}{lll}\text { A17 } & \text { BRCA2 } & \text { c.8869C }>\text { T }\end{array}$

\begin{tabular}{lll}
\hline A18 & BRCA2 & c.7878G $>C$ \\
\hline$A 32$ & MSH2 & c.1906G $>C$
\end{tabular}

$\begin{array}{lll}\text { A32 } & \text { MSH2 } & \text { C.1906G }>C\end{array}$

$\begin{array}{lll}\text { B23 BRCA2 } & \text { c.5946delT }\end{array}$

B24 BRCA2 C.1796_1800delCTTAT

B28 BRCA2 c.5946delT

A19 CHEK2 c.1100delC

A20 CHEK2 c.1283C $>$ T

$\begin{array}{lll}\text { B21 CHEK2 C.1283C }>\text { T } & \end{array}$

\begin{tabular}{lll}
\hline B51 CHEK2 & c.444+1G $>$ A
\end{tabular}

B57 CHEK2 C.1283C $>$ T

A40 PALB2 C.940C $>T$

$\begin{array}{lll}\text { B109 APC } & \text { C.3920T }>\text { A }\end{array}$

B180 BLM c.2207_2212delinsTAGATTC p

\begin{tabular}{|c|c|c|c|c|c|c|c|c|}
\hline B47 & CHEK2 & c. $470 T>C$ & p.lle157Thr & Uncertain & $\mathrm{LOH}$ & Upper tract & Yes & Identified \\
\hline A11 & ERCC2 & c. $1847 G>C$ & p.Arg616Pro & Recessive & $\mathrm{LOH}$ & Bladder & Yes & Anonymized \\
\hline A25 & ERCC3 & c. $325 C>T$ & p.Arg109Ter & Moderate & No LOH & Bladder & Yes & Anonymized \\
\hline A26 & ERCC3 & c. $325 C>T$ & p.Arg109Ter & Moderate & No LOH & Bladder & Yes & Anonymized \\
\hline A22 & ERCC2 & c. $2150 C>G$ & p.Ala717Gly & Recessive & Somatic & Bladder & Yes & Anonymized \\
\hline
\end{tabular}


TABLE A4. Detail on Pathogenic/Likely Pathogenic Germline Variants (continued)

\begin{tabular}{|c|c|c|c|c|c|c|c|c|}
\hline Study ID & Gene & Variant & Protein & Penetrance & Zygosity & Site & DDR Gene & Cohort \\
\hline A6 & MSH2 & c. $1906 \mathrm{G}>\mathrm{C}$ & p.Ala636Pro & High & Somatic & Upper tract & Yes & Anonymized \\
\hline A27 & ERCC3 & c. $325 \mathrm{C}>\mathrm{T}$ & p.Arg109Ter & Moderate & No LOH & Bladder & Yes & Anonymized \\
\hline B20 & ERCC3 & c. $325 \mathrm{C}>\mathrm{T}$ & p.Arg109Ter & Moderate & No LOH & Bladder & Yes & Identified \\
\hline A23 & ERCC2 & c. $1847 G>C$ & p.Arg616Pro & Recessive & $\mathrm{LOH}$ & Bladder & Yes & Anonymized \\
\hline A24 & ERCC3 & c.576_583delCGTGATCC & p.Val193ArgfsTer8 & Recessive & $\mathrm{LOH}$ & Bladder & Yes & Anonymized \\
\hline A28 & $\mathrm{FH}$ & c.1431_1433dupAAA & p.Lys477dup & Recessive & No LOH & Bladder & No & Anonymized \\
\hline B101 & $\mathrm{MSH} 2$ & c. $1906 \mathrm{G}>\mathrm{C}$ & p.Ala636Pro & High & Somatic & Upper tract & Yes & Identified \\
\hline A29 & $\mathrm{FH}$ & c.1431_1433dupAAA & p.Lys477dup & Recessive & $\mathrm{LOH}$ & Bladder & No & Anonymized \\
\hline B109 & MSH6 & c.3261dupC & p.Phe1088Leufs*5 & High & No LOH & Upper tract & Yes & Identified \\
\hline B111 & MSH6 & c. $3463 C>T$ & p.G $\ln 1155^{*}$ & High & Somatic & Upper tract & Yes & Identified \\
\hline B161 & MITF & c. $952 \mathrm{G}>\mathrm{A}$ & p.Glu318Lys & Moderate & No LOH & Bladder & No & Identified \\
\hline A30 & MRE11A & c.1222dupA & p.Thr408AsnfsTer49 & Moderate & No LOH & Bladder & Yes & Anonymized \\
\hline A31 & $\mathrm{MSH} 2$ & c. $1255 \mathrm{C}>\mathrm{T}$ & p.GIn419Ter & High & Somatic & Bladder & Yes & Anonymized \\
\hline B100 & MSH2 & c. $1216 \mathrm{C}>\mathrm{T}$ & p.R406* & High & $\mathrm{LOH}$ & Bladder & Yes & Identified \\
\hline B70 & $\mathrm{FH}$ & c.1431_1433dupAAA & p.Lys477dup & Recessive & No LOH & Bladder & No & Identified \\
\hline B14 & $B R C A 1$ & c.68_69delAG & p.Glu23Valfs*17 & High & $\mathrm{CNLOH}$ & Upper tract & Yes & Identified \\
\hline B61 & $\mathrm{FH}$ & c.1431_1433dupAAA & p.Lys477dup & Recessive & No LOH & Upper tract & No & Identified \\
\hline A33 & MUTYH & c. $536 \mathrm{~A}>\mathrm{G}$ & p.Tyr179cys & Low & No LOH & Bladder & Yes & Anonymized \\
\hline A34 & MUTYH & c. $1187 \mathrm{G}>\mathrm{A}$ & p.Gly396Asp & Low & No LOH & Bladder & Yes & Anonymized \\
\hline A35 & MUTYH & c. $536 \mathrm{~A}>\mathrm{G}$ & p.Tyr179cys & Low & No LOH & Bladder & Yes & Anonymized \\
\hline B174 & MLH1 & c.1591delG & p.Val531Trpfs*4 & High & $\mathrm{LOH}$ & Upper tract & Yes & Identified \\
\hline A36 & MUTYH & c. $1187 \mathrm{G}>\mathrm{A}$ & p.Gly396Asp & Low & No LOH & Bladder & Yes & Anonymized \\
\hline A38 & $N B N$ & c. $2140 \mathrm{C}>\mathrm{T}$ & p.Arg714Ter & Moderate & No LOH & Bladder & Yes & Anonymized \\
\hline A39 & $N B N$ & c.657_661delACAAA & p.Lys219AsnfsTer16 & Moderate & No LOH & Bladder & Yes & Anonymized \\
\hline B119 & $N B N$ & c. $2 \mathrm{~T}>\mathrm{C}$ & p.Met1Thr & Moderate & No LOH & Bladder & Yes & Identified \\
\hline A41 & RAD50 & c.326_329delCAGA & p.Thr109AsnfsTer20 & Moderate & No LOH & Bladder & Yes & Anonymized \\
\hline A42 & RAD50 & c.1270_1271delCT & p.Leu424GlufsTer7 & Moderate & No LOH & Bladder & Yes & Anonymized \\
\hline A43 & RAD50 & c. $2467 C>T$ & p.Arg823Ter & Moderate & No LOH & Bladder & Yes & Anonymized \\
\hline B139 & RAD51C & Exons 1-3 deletion & & Moderate & No LOH & Bladder & Yes & Identified \\
\hline A37 & MUTYH & c. $1187 \mathrm{G}>\mathrm{A}$ & p.Gly396Asp & Low & No LOH & Bladder & Yes & Anonymized \\
\hline B43 & $B R I P 1$ & c. $918+1 G>A$ & & Moderate & $\mathrm{LOH}$ & Upper tract & Yes & Identified \\
\hline B118 & MUTYH & c. $536 A>G$ & p.Tyr179Cys & Low & No LOH & Bladder & Yes & Identified \\
\hline B5 & ATM & c. $748 \mathrm{C}>\mathrm{T}$ & p.Arg250* & Moderate & $\mathrm{CNLOH}$ & Upper tract & Yes & Identified \\
\hline A45 & $S D H A$ & c.245_252delAGGCAGGG & p.Glu82ValfsTer2 & High & $\mathrm{LOH}$ & Bladder & No & Anonymized \\
\hline B159 & $S D H A$ & c. $1 A>G$ & p.Met1Val & High & No LOH & Bladder & No & Identified \\
\hline A44 & RECQL4 & c. $2464-1 G>C$ & & Recessive & $\mathrm{LOH}$ & Bladder & Yes & Anonymized \\
\hline B127 & TP53 & c. $374 C>T$ & p.Thr125Met & High & Somatic & Bladder & No & Identified \\
\hline B71 & MLH1 & c. $790+2 T>C$ & & High & $\mathrm{LOH}$ & Upper tract & Yes & Identified \\
\hline B73 & $\mathrm{MSH} 2$ & c. $1046 C>G$ & p.Pro349Arg & High & Somatic & Upper tract & Yes & Identified \\
\hline B79 & MSH2 & c. $942+3 \mathrm{~A}>\mathrm{T}$ & & High & Hom del & Upper tract & Yes & Identified \\
\hline B85 & $\mathrm{MSH} 2$ & c. $1784 \mathrm{~T}>\mathrm{G}$ & p.L595R & High & No LOH & Upper tract & Yes & Identified \\
\hline A46 & $A P C$ & c.3920T>A & p.lle1307Lys & Low & $\mathrm{LOH}$ & Upper tract & No & Anonymized \\
\hline A46 & BRCA2 & c.5722_5723delCT & p.Leu1908ArgfsTer2 & High & $\mathrm{LOH}$ & Upper tract & Yes & \\
\hline
\end{tabular}

Abbreviations: CNLOH, copy neutral loss of heterozygosity; DDR, DNA-damage repair; Hom del, homologous deletion; LOH, loss of heterozygosity; mt, mutation. 
TABLE A5. Germline Mutations Identified by Sequencing and Clinical Criteria in Identified Cohort

\section{Genetic Mutation}

No. Identified by No. (\%) Identified by Sequencing Clinical Criteria

\begin{tabular}{lll}
\hline $\begin{array}{l}\text { All high- or moderate-penetrance } \\
\text { mutations }\end{array}$ & 26 & 14 (53) \\
\hline MSH2/MLH1/MSH6 & 9 & $6(75)$ \\
\hline BRCA1/BRCA2 & 8 & $7(88)$ \\
\hline CHEK2 & 2 & $1(33)$ \\
\hline RAD51C & 1 & 0 \\
\hline BRIP1 & 1 & 0 \\
\hline SDHA & 1 & 0 \\
\hline TP53 & 1 & 0 \\
\hline MITF & 1 & 0 \\
\hline ATM & 1 & 0 \\
\hline NBN & 1 & 0 \\
\hline ERCC3 & 1 & $1^{*}$
\end{tabular}

*Patient met criteria for $B R C A$ testing. 